\title{
Small-bowel capsule endoscopy and device-assisted enteroscopy for diagnosis and treatment of small-bowel disorders: European Society of Gastrointestinal Endoscopy (ESGE) Technical Review
}

\section{(द) ESGE}

Authors

Emanuele Rondonotti ${ }^{1}$, Cristiano Spada ${ }^{2,3}$, Samuel Adler ${ }^{4}$, Andrea May ${ }^{5}$, Edward J. Despott ${ }^{6}$, Anastasios Koulaouzidis ${ }^{7}$, Simon Panter ${ }^{8}$, Dirk Domagk ${ }^{9}$, Ignacio Fernandez-Urien ${ }^{10}$, Gabriel Rahmi ${ }^{11}$, Maria Elena Riccioni ${ }^{2}$, Jeanin E. van Hooft ${ }^{12}$, Cesare Hassan ${ }^{13}$, Marco Pennazio ${ }^{14}$

Institutions

1 Gastroenterology Unit, Ospedale Valduce, Como, Italy

2 Digestive Endoscopy Unit, Catholic University of Rome, Rome, Italy

3 Digestive Endoscopy Unit, Fondazione Poliambulanza, Brescia, Italy

4 Division of Gastroenterology, Shaare Zedek Medical Center, Jerusalem, Israel

5 Department of Medicine II, Sana Klinikum, Offenbach, Germany

6 Royal Free Unit for Endoscopy, Centre for Gastroenterology, The Royal Free Hospital \& University College London, London, UK

7 Endoscopy Unit, The Royal Infirmary of Edinburgh, Scotland, UK

8 Department of Gastroenterology, South Tyneside Hospital, South Shields, UK

9 Department of Medicine B, University of Münster, Münster, Germany

10 Department of Gastroenterology, Hospital de Navarra, Pamplona, Spain

11 Department of Gastroenterology and Digestive Endoscopy, Georges Pompidou European Hospital, Assistance Publique-Hôpitaux de Paris, Paris, France

12 Department of Gastroenterology and Hepatology, Academic Medical Center, Amsterdam, Netherlands

13 Endoscopy Unit, Nuovo Regina Margherita Hospital, Rome, Italy

14 Division of Gastroenterology U, Azienda OspedalieroUniversitaria, Città della Salute e della Scienza, Turin, Italy

\section{Bibliography}

DOI https://doi.org/10.1055/a-0576-0566

Published online: 14.3.2018 | Endoscopy 2018; 50: 423-446

(c) Georg Thieme Verlag KG Stuttgart · New York

ISSN 0013-726X
Corresponding author

Emanuele Rondonotti, MD PhD, Gastroenterology Unit,

Ospedale Valduce, via Dante 10, 22100, Como, Italy

Fax: +39-031-324150

ema.rondo@gmail.com

\# Appendix e1-e3

Online content viewable at:

https://doi.org/10.1055/a-0576-0566

\section{MAIN RECOMMENDATIONS}

Small-bowel capsule endoscopy (SBCE)

1 ESGE recommends that prior to SBCE patients ingest a purgative ( $2 \mathrm{~L}$ of polyethylene glycol [PEG]) for better visualization.

Strong recommendation, high quality evidence.

However, the optimal timing for taking purgatives is yet to be established.

2 ESGE recommends that SBCE should be performed as an outpatient procedure if possible, since completion rates are higher in outpatients than in inpatients.

Strong recommendation, moderate quality evidence.

3 ESGE recommends that patients with pacemakers can safely undergo SBCE without special precautions.

Strong recommendation, low quality evidence.

4 ESGE suggests that SBCE can also be safely performed in patients with implantable cardioverter defibrillators and left ventricular assist devices.

Weak recommendation, low quality evidence.

5 ESGE recommends the acceptance of qualified nurses and trained technicians as prereaders of capsule endoscopy studies as their competency in identifying pathology is similar to that of medically qualified readers. The responsibility of establishing a diagnosis must however remain with the attending physician.

Strong recommendation, moderate quality evidence. 
6 ESGE recommends observation in cases of asymptomatic capsule retention.

Strong recommendation, moderate quality evidence.

In cases where capsule retrieval is indicated, ESGE recommends the use of device-assisted enteroscopy as the method of choice.

Strong recommendation, moderate quality evidence.

\section{Device-assisted enteroscopy (DAE)}

1 ESGE recommends performing diagnostic DAE as a daycase procedure in patients without significant underlying co-morbidities; in patients with co-morbidities and/or those undergoing a therapeutic procedure, an inpatient stay is recommended.

Strong recommendation, low quality evidence

The choice between different settings also depends on sedation protocols.

Strong recommendation, low quality evidence.

2 ESGE suggests that conscious sedation, deep sedation, and general anesthesia are all acceptable alternatives: the choice between them should be governed by procedure complexity, clinical factors, and local organizational protocols.

Weak recommendation, low quality evidence.

3 ESGE recommends that the findings of previous diagnostic investigations should guide the choice of insertion route.

Strong recommendation, moderate quality evidence.
If the location of the small-bowel lesion is unknown or uncertain, ESGE recommends that the antegrade route should be generally preferred.

Strong recommendation, low quality evidence.

In the setting of massive overt bleeding, ESGE recommends an initial antegrade approach.

Strong recommendation, low quality evidence.

4 ESGE recommends that, for balloon-assisted enteroscopy (i.e., single-balloon enteroscopy [SBE] and double-balloon enteroscopy [DBE]), small-bowel insertion depth should be estimated by counting net advancement of the enteroscope during the insertion phase, with confirmation of this estimate during withdrawal.

Strong recommendation, low quality evidence.

ESGE recommends that, for spiral enteroscopy, insertion depth should be estimated during withdrawal.

Strong recommendation, moderate quality evidence.

Since the calculated insertion depth is only a rough estimate, ESGE recommends placing a tattoo to mark the identified lesion and/or the deepest point of insertion.

Strong recommendation, low quality evidence.

5 ESGE recommends that all endoscopic therapeutic procedures can be undertaken at the time of DAE.

Strong recommendation, moderate quality evidence.

Moreover, when therapeutic interventions are performed, additional specific safety measures are needed to prevent complications.

Strong recommendation, high quality evidence.
This Technical Review complements the recent European Society of Gastrointestinal Endoscopy (ESGE) Clinical Guideline on small-bowel capsule endoscopy (SBCE) and device-assisted enteroscopy (DAE) for the diagnosis and treatment of small-bowel disorders. The aim of this complementary Technical Review is to discuss technical issues relating to the use of both SBCE and DAE, providing guidance for clinicians on optimal performance of these procedures in clinical practice.

\section{Introduction and aim}

Small-bowel capsule endoscopy (SBCE) and device-assisted enteroscopy (DAE) have been used in clinical practice in Western countries since 2001 and 2005, respectively. Their combined use has revolutionized the approach to the investigation and management of small-bowel pathology, modifying well-established clinical models (e.g. the definition of obscure gastrointestinal bleeding) [1] and leading to the development of new diagnostic and therapeutic algorithms [1,2].

In 2015, the European Society of Gastrointestinal Endoscopy (ESGE) issued a Clinical Guideline [2] that focused mainly on the role of SBCE and DAE for diagnosis and management of smallbowel disorders; technical and practical aspects were not discussed. Similarly, in other reviews and guidelines [3 -8] technical matters such as preparation schedule, reading/reporting protocols, sedation regimens, and choice of DAE insertion route (which have been shown to impact on the diagnostic and therapeutic yield $[9,10]$ ) are only partially addressed.

In order to complement the 2015 Clinical Guideline, ESGE commissioned and funded this comprehensive evidence-based Technical Review. The endoscopic technique itself has already been described in detail elsewhere $[3,4-8,11,12]$; this Technical Review therefore focuses on other unaddressed SBCE- and DAE-related technical issues, in order to provide guidance for clinicians on the optimal use of these technologies in clinical practice.

\section{Methods}

The procedure definitions adopted in the present Technical Review are in line with those of the Clinical Guideline [2]. DAE includes double-balloon enteroscopy (DBE), single-balloon enteroscopy (SBE), spiral enteroscopy, and balloon-guided endoscopy (BGE). The evidence concerning the latter technique is very limited, thus the present Technical Review is focused on DBE, SBE, and spiral enteroscopy (DBE and SBE being grouped together as balloon-assisted enteroscopy [BAE]). Since some DAE technical issues differ completely between adult and pediatric patients [13-15], the present Technical Review focuses on the management of adult patients. 


\begin{tabular}{|c|c|}
\hline \multicolumn{2}{|c|}{ ABBREVIATIONS } \\
\hline ALICE & $\begin{array}{l}\text { augmented live-body image color spectrum } \\
\text { enhancement }\end{array}$ \\
\hline APC & argon plasma coagulation \\
\hline ASA & American Society of Anesthesiologists \\
\hline BAE & balloon-assisted enteroscopy \\
\hline BGE & balloon-guided endoscopy \\
\hline BIS & bispectral \\
\hline BM & blue mode \\
\hline CCD & charge-coupled device \\
\hline CECDAI & $\begin{array}{l}\text { Capsule Endoscopy Crohn's Disease Activity } \\
\text { Index }\end{array}$ \\
\hline CMOS & complementary metal oxide semiconductor \\
\hline $\mathrm{CO}_{2}$ & carbon dioxide \\
\hline CT & computed tomography \\
\hline DAE & device-assisted enteroscopy \\
\hline DBE & double-balloon enteroscopy \\
\hline DPE & direct percutaneous endoscopic jejunostomy \\
\hline EBD & endoscopic balloon dilation \\
\hline ERCP & $\begin{array}{l}\text { endoscopic retrograde cholangiopancreato- } \\
\text { graphy }\end{array}$ \\
\hline ESGE & European Society of Gastrointestinal Endoscopy \\
\hline FICE & flexible spectral imaging color enhancement \\
\hline GRADE & $\begin{array}{l}\text { Grading of Recommendations Assessment, } \\
\text { Development and Evaluation }\end{array}$ \\
\hline IBD & inflammatory bowel disease \\
\hline ICD & implantable cardioverter defibrillator \\
\hline LED & light-emitting diode \\
\hline LVAD & left ventricular assist device \\
\hline MAC & monitored anesthesia care \\
\hline NSAID & nonsteroidal anti-inflammatory drug \\
\hline OR & odds ratio \\
\hline PEG & polyethylene glycol \\
\hline RCT & randomized controlled trial \\
\hline ROC & receiver operating characteristic \\
\hline SBCE & small-bowel capsule endoscopy \\
\hline SBE & single-balloon enteroscopy \\
\hline SBFT & small-bowel follow-through \\
\hline SPICE & $\begin{array}{l}\text { Smooth Protruding lesion Index on Capsule } \\
\text { Endoscopy }\end{array}$ \\
\hline
\end{tabular}

ESGE appointed a coordinating team (E.R., C.S., and M.P.), who formed two working groups (one for SBCE and one for DAE) and identified two group leaders (S.A. for SBCE and A.M. for DAE) (Appendix e1, see online-only Supplementary material). Each working group was charged with a series of topicspecific key questions (Appendix e2, online-only Supplementary material) and performed a dedicated systematic literature search, including as a minimum the following key words: smallbowel capsule endoscopy, device-assisted enteroscopy, double-balloon enteroscopy, single-balloon enteroscopy, spiral enteroscopy, balloon-assisted enteroscopy, small-bowel, capsule endoscopy, and enteroscopy, as appropriate. All retrieved papers were evaluated by checking the title, abstract, and full text. The systematic literature search was performed in July
2016. A nonsystematic literature search was repeated, when appropriate, through March 2017 (this date should be taken into account for future updates).

All selected articles were graded by the level of evidence and strength of recommendation; statements were provided by the two working groups, according to the Grading of Recommendations Assessment, Development and Evaluation (GRADE) system $[16,17]$. During a dedicated meeting in October 2016, the statements were presented, discussed, modified, and finally approved by consensus. The coordinating team drafted a manuscript, which was eventually reviewed, modified, and approved by the working group leaders. The paper was sent for internal review to all individual ESGE members in July 2017. After incorporation of their comments, the ESGE Governing Board endorsed it, prior to submission to Endoscopy for international peer review.

This Technical Review will be considered for review in 2022, or sooner if important new evidence becomes available. Any updates in the interim period will be noted on the ESGE website: http://www.esge.com/esge-guidelines.html.

\section{Statements and recommendations on small-bowel capsule endoscopy (SBCE)}

\subsection{Commercially available devices}

Available devices and their main technological features are listed in Table 1 in Appendix e3 (online-only Supplementary material).

\subsection{Preparation}

\section{RECOMMENDATION}

ESGE recommends that prior to SBCE patients follow a modified diet.

Strong recommendation, low quality evidence.

\section{RECOMMENDATION}

ESGE recommends that patients ingest a purgative ( $2 \mathrm{~L}$ of polyethylene glycol [PEG]) prior to SBCE for better visualization.

Strong recommendation, high quality evidence.

The optimal timing for taking purgatives is yet to be established. Prokinetics do not improve completion rate of SBCE and their routine administration is not recommended.

Strong recommendation, high quality evidence. 


\section{RECOMMENDATION}

ESGE recommends administration of antifoaming agents before capsule ingestion.

Strong recommendation, high quality evidence.

Optimal patient preparation for SBCE has been controversial. Given Imaging (Yoqneam, Israel), the first manufacturer of capsule endoscopes, did not recommend preprocedure purgative use for SBCE; the only recommended requirements were a low-fiber diet on the day before the procedure with clear liquids only in the evening and a 12-hour fast. Indeed, this protocol was used in the controlled studies of obscure gastrointestinal bleeding and of suspected or established Crohn's disease. In 2007, after reviewing the value of bowel lavage prior to SBCE, the first expert consensus paper on SBCE concluded: "the current evidence mainly from fully published papers suggests the PEG lavage and simethicone both positively affect mucosal visibility and perhaps also diagnostic yield" [18]. Eight randomized controlled studies have addressed the question of whether purgatives improve mucosal visibility, diagnostic yield, and completion rate $[12,19-25]$. To date, four meta-analyses have concluded that the ingestion of $2 \mathrm{~L}$ of PEG solution prior to capsule ingestion leads to improved visibility of the small-bowel mucosa. However, the evidence relating to completion rates and diagnostic yield is still inconclusive and the optimal timing for purgative use is yet to be established [26-29].

A meta-analysis of four randomized controlled trials (RCTs) evaluating the role of prokinetics in SBCE concluded that prokinetic use alone was ineffective at increasing SBCE completion rates [30]. Conversely, patients with increased risk for an incomplete SBCE study (for example, in patients or patients with one or more of the following conditions: previous history of abdominal surgery, delayed gastric emptying, diabetic neuropathy, severe hypothyroidism, use of psychotropic drugs etc.) may benefit from the administration of certain prokinetics (metoclopramide or domperidone), when the capsule remains in the stomach for more than 30-60 minutes as confirmed by real-time monitoring [30]. Some RCTs demonstrate that antifoaming agents improve the quality of mucosal visualization [20,31-33] and two meta-analyses have concluded that simethicone significantly decreases the presence of small-bowel bubbles/foam [28,34]. The optimal dose of simethicone is yet to be defined and ranges between 80 to $200 \mathrm{mg}$ [20,31 - 34].

\subsection{Setting}

\section{RECOMMENDATION}

ESGE recommends that SBCE should be performed as an outpatient procedure if possible, since completion rates are higher in outpatients than in inpatients.

Strong recommendation, moderate quality evidence.
Evidence in the literature supports that an inpatient setting is more often associated with an incomplete SBCE procedure $[35,36]$. A cohort study of 334 consecutive patients undergoing SBCE (264 outpatient and 70 inpatient procedures) was analyzed retrospectively [35]. The capsule did not enter the small bowel in 6/70 inpatients versus $8 / 264$ outpatients $(P=0.04)$. The capsule did not reach the cecum in $31.4 \%$ of inpatient studies versus $9.5 \%$ of outpatient studies $(P<0.001)$. Mean gastric transit time was prolonged in inpatients (98.5 minutes) versus outpatients (60.4 minutes, $P=0.008)$. Among inpatients, the proportion of incomplete exams was higher in an intensive care unit setting $(7 / 13,54 \%)$ than a general medical ward setting $(15 / 57,26 \%)(P=0.05)$. Although there are no clear-cut explanations for these findings, the number and severity of comorbidities, use of medications which may affect small-bowel transit time, as well as the reduced physical activity of inpatients, have been postulated as potential contributing factors. In another prospective study, 76 patients undergoing SBCE were enrolled to assess the relationship of physical activity to completion rates [37]. The SBCE completion rate was $100 \%$ $(23 / 23)$ in the outpatient group, $85.7 \%(30 / 35)$ in the "mild bed-rest" group, and $72.2 \%(13 / 18)$ in the "strict bed-rest" group. Reduced physical activity was a significant risk factor for incomplete SBCE examination (adjusted odds ratio [OR] 3.39) [37].

In some clinical scenarios the timing of SBCE is a crucial issue. In patients with acute overt bleeding, clinical guidelines [2] suggest performing SBCE as soon as possible after the bleeding episode (ideally within 24-72 hours). When clinically indicated, the examination should not be postponed simply because the patient is an inpatient. In such situations, however, a higher rate of incomplete examinations has to be expected because of a prolonged transit time in critically ill patients who are more likely to be confined to bed; therefore, all those practices that would favor a complete examination (see section 3.4) should be implemented.

\subsection{The role of real-time monitoring}

\section{RECOMMENDATION}

ESGE recommends the use of a real-time viewer, particularly in patients who are at risk of delayed gastric emptying and who may experience gastric capsule retention. In these cases, a real-time viewer may guide appropriate intervention (administration of a prokinetic agent and/or endoscopically assisted capsule delivery into the duodenum) to optimize the SBCE examination.

Strong recommendation, low quality evidence.

Currently, real-time viewers are incorporated into several SBCE systems. Although unpublished data on the experience of hundreds of healthy volunteers shows that capsule passage through the stomach usually occurs within 4 hours of capsule ingestion (in 97\%-100\%), patients at risk of delayed gastric emptying may have a failed SBCE exam because of transient capsule retention within the stomach. This subgroup includes 
inpatients, patients with diabetic neuropathy, severe hypothyroidism, or renal insufficiency, and/or those using psychotropic or narcotic medications. Such patients may benefit from the use of a real-time viewing system, to guide pre-emptive intervention in the case of capsule gastric retention.

A prospective study by Hosono et al. [38] from Japan compared SBCE performance in 80 patients with or without realtime viewing. In the real-time viewing group, $10 \mathrm{mg}$ of metoclopramide, followed by $500 \mathrm{~mL}$ of PEG was given if the capsule had failed to pass through the stomach at 60 minutes post-ingestion. The completion rate in the real-time viewing group was significantly higher than in the control group ( $90 \%$ vs. $72.5 \%)$. Shiotani et al. [39] have recently compared the proportion of completed exams and positive results among a group of patients studied before introduction of real-time viewing and a group in which capsule transit through the esophagus, stomach, and small bowel was regularly monitored and action was taken (e. g. administration of water or intravenous metoclopramide) if it was delayed. They found that the use of a real-time viewer increased SBCE completion rates from $66 \%$ to $86 \%(P=$ $0.002)$. Ogata et al. found that the real-time viewer was useful in identifying patients with gastric transit times longer than 1 hour and that the oral administration of $10 \mathrm{mg}$ of metoclopramide was useful in this setting [40].

\subsection{Procedure-related and special situation-related precautions}

\section{RECOMMENDATION}

ESGE suggests that patients should fast for at least 2 hours after capsule ingestion. Patients may be allowed to drink clear liquids 2 hours after capsule ingestion, and to eat solid food 4 hours after capsule ingestion.

Weak recommendation, very low quality evidence.

\section{RECOMMENDATION}

ESGE recommends that patients with a pacemaker can safely undergo SBCE without special precautions. Strong recommendation, low quality evidence. ESGE suggests that SBCE can also be safely performed in patients with implantable cardioverter defibrillators (ICDs) and left ventricular assist devices (LVADs).

Weak recommendation, low quality evidence.

\subsubsection{Food and water ingestion}

When SBCE was introduced into clinical practice, manufacturers recommended that patients may drink water 2 hours after capsule ingestion and may eat 4 hours after capsule ingestion. In the absence of studies evaluating the effect of the timing of water and/or food ingestion on capsule view quality and/or transit time, at present, expert opinion supports adherence to this regimen. Nevertheless, recent experience, mainly derived from studies focused on preparation regimens for colon cap- sule endoscopy, suggests that earlier ingestion of clear liquids may enhance capsule view quality and propulsion.

\subsubsection{Electromagnetic interference with other devices}

Technical specifications of capsules that use radiofrequencies for data transmission demonstrate that the maximum transmission power is usually below the permitted limits for cardiac devices [41,42]. Hence, impairment of implanted cardiac devices by SBCE is unlikely. Nevertheless, SBCE users are concerned that possible interference between capsules and cardiac devices could be life-threatening for patients. Therefore, since the introduction of SBCE, several in vitro [43-45] and in vivo [4558] studies have analyzed electromagnetic interference between SBCE and implantable cardiac devices (i. e., pacemakers, implantable cardioverter defibrillators [ICDs], and LVADs). Bandorski et al. [46] (data from 2010) reported a retrospective study on 300 patients with cardiac pacemakers who had undergone SBCE despite the formal contraindication stated by manufacturers; no adverse events had occurred. Subsequently, other authors investigated in vivo the potential interaction of SBCE with pacemakers and confirmed that no clinically relevant interference occurred either way [45-53,59].

At present, fewer data are available on SBCE patients with ICDs [45, 46, 48, 49,55-58] or LVADs [60-65], mostly because of the relative rarity of clinical conditions requiring their implant. However the available evidence on the safety of SBCE in this subset of patients seems to be reassuring. Although Dubner et al., in an in vitro study [45], described oversensing of ICDs and inappropriate shock delivery, so far several case reports and case series (involving more than 100 patients overall) reported that no significant interference was found in patients with ICDs. Similarly, in the case reports and case series, involving overall approximately 90 patients with LVADs undergoing SBCE [60-65], no hemodynamic, electronic, or mechanical abnormalities or malfunctions of LVADs were observed, whereas short interference (loss of images) in SBCE image acquisition has been described. Regarding capsules without radiofrequency data transmission, one study investigating a capsule that uses the human body for data transmission (including $3 \mathrm{pa}$ tients with pacemakers and 3 patients with ICDs) did not report any interference in either direction [66]; for capsules with onboard storage of images without transmission, interference with cardiac devices is not possible [41].

In light of all these data, the presence of implanted cardiac devices should no longer be seen as a contraindication for SBCE when it is clinically indicated. During the SBCE recording, patients with implanted cardiac devices should avoid areas containing instruments/devices generating strong electromagnetic fields (e.g. cardiology units using telemetric monitoring, radiology units, etc.), because they may interfere with capsule data recording $[46,49,52]$. Therefore, systematic telemetric monitoring is not recommended in patients with implanted cardiac devices who are undergoing SBCE; if cardiac monitoring is necessary during SBCE, wired systems should be used [41].

Recently, interference has been reported between capsule endoscopy and the second-generation OmniPod patch pump, 
which shares the same radiofrequency [67], whereas mobile phones do not appear to interfere with SBCE imaging.

\subsubsection{Pregnancy}

Only a few cases of capsule endoscopy during pregnancy have been reported $[68,69]$. Although the reported cases resulted in favorable maternal and fetal outcomes, current data are insufficient to make any specific recommendation. Experts suggest that, at the present time, capsule endoscopy is considered to be contraindicated during pregnancy, but it might be considered in the case of life-threatening conditions, such as massive life-threatening bleeding, after a full discussion with the patient and due consideration of the potential risks and benefits.

\subsection{Post-procedure precautions}

\section{RECOMMENDATION}

ESGE recommends that a plain abdominal X-ray should be performed in patients with an incomplete capsule study (capsule not reaching the colon or stoma bag) if they do not notice capsule egestion after 15 days.

Strong recommendation, moderate quality evidence.

Capsule retention is arbitrarily defined as the identification of a capsule endoscope on abdominal radiological imaging $\geq 14$ days after capsule ingestion [70]. Patients undergoing SBCE should be instructed to check for egestion of the capsule endoscope and to report any relevant symptom that may potentially suggest capsule retention. In asymptomatic patients who do not notice capsule egestion within 2 weeks of ingestion, an abdominal radiograph should generally be obtained to rule out capsule retention. Abdominal radiographic imaging may be avoided if the capsule recording confirms passage into the colon, since the risk of capsule retention in these patients appears negligible $[70,71]$.

Regarding the management of patients with capsule retention, please refer to section 3.10.

\subsection{Capsule endoscopy readers}

\section{RECOMMENDATION}

ESGE recommends the acceptance of qualified nurses and trained technicians as prereaders of capsule endoscopy studies as their competency in identifying pathology is similar to that of medically qualified readers. The responsibility of establishing a diagnosis must however remain with the attending physician.

Strong recommendation, moderate quality evidence.

The available evidence confirms that, after adequate training, nurses and/or other technical staff are able to identify pathology as well as physicians [72-76]. It is therefore acceptable for physicians to rely on adequately trained and qualified prereaders. The ultimate diagnostic responsibility, and interpreta- tion of the capsule findings within the particular clinical context, must however remain with the attending physician.

\subsection{Small-bowel capsule endoscopy reading protocols}

\section{RECOMMENDATION}

ESGE suggests that SBCE recordings should be read at a maximum speed of 10 frames per second in a singleview mode. Double- and multiple-view modes, if available, at a maximum speed of 20 frames per second are also viable alternatives.

Weak recommendation, low quality evidence.

\section{RECOMMENDATION}

ESGE suggests slowing down the frame rate, below the thresholds recommended above, when evaluating the proximal small bowel.

Strong recommendation, low quality evidence.

\section{RECOMMENDATION}

ESGE suggests that automated fast reading software may be used in conditions affecting the small-bowel mucosa diffusely, but this should never replace conventional reading.

Weak recommendation, moderate quality evidence.

\section{RECOMMENDATION}

ESGE does not recommend the routine use of virtual chromoendoscopy during reading of the capsule recording since it does not appear to improve lesion detection or characterization.

Strong recommendation, high quality evidence.

There are no evidence-based recommendations regarding optimal frame rate for reading SBCE recordings. However, since SBCE reading is a time-consuming process, several options have been evaluated with the aim of saving time without compromising lesion detection rate. These include view mode (automatic vs. manual), frame rate (number of images viewed per second), single-frame versus multiframe views, and automated viewing applications. Automatic mode, which eliminates similar images, results in a significant reduction of reading time (by up to $50 \%$ ) with a very low diagnostic miss rate when compared with manual mode $[77,78]$. On the other hand, the impact of viewing frame rate on lesion detection is not clear. While some authors have demonstrated low diagnostic miss rates regardless of viewing frame rate $[77,79]$, others have concluded that increasing the viewing frame rate may result in lesions being missed $[80,81]$. Most studies have selected a 
viewing frame rate of 10 frames per second in single-view mode as the "reference standard." Although direct evidence is lacking, several studies have reported that SBCE lesion miss rate is higher in the proximal small bowel [82-84]. Factors which may contribute to higher lesion miss rates in this region include faster capsule propulsion through sharply angulated segments, and the presence of bile and foam which may obscure mucosal views. Therefore, expert opinion suggests decreasing the viewing frame rate when evaluating the proximal small bowel [8588]. In addition, other factors potentially affecting the reviewing speed are reader expertise (a highly experienced reader can read an SBCE video with a higher frame rate compared to a beginner), SBCE capsule progression speed, and quality of smallbowel preparation (if the capsule passes very quickly or the quality of view is low, the reader has to decrease the frame rate).

Four studies have evaluated the effects of multiframe vs. single-frame views, on reading time and lesion detection [77, 79-81]. Multiframe modes appear to save time without compromise of lesion detection (especially for diffuse pathology such as that found in inflammatory bowel disease [IBD]), when compared with a single-frame viewing mode. Most of the evidence relating to automated fast-viewing applications comes from studies relating to the QuickView mode, an automated fast reading mode available on Rapid software (Medtronic, Dublin, Ireland). Although it has been demonstrated to definitively save time, this potential benefit is offset by an unacceptable lesion miss rate, ranging from $6.5 \%$ to $12 \%[78,89,90]$. The majority of missed lesions were single isolated lesions (such as polyp, vascular, or isolated inflammatory lesions). Despite this shortcoming, it may still have a role in conditions associated with diffuse small-bowel pathology such as IBD. In fact the agreement between automated fast reading and conventional viewing was higher when the indication for the procedure was suspected IBD.

In light of the fact that currently the images acquired at SBCE are not of high resolution, the potential roles of any image-enhancement tool are: (a) to improve the detection rate for clinically relevant lesions; (b) to allow more accurate characterization/definition of observed lesions; and/or (c) to provide a new classification system for lesions in order to have an impact on patient outcomes (e. g., to identify those lesions that require treatment) [91]. In 2005, flexible spectral imaging color enhancement (FICE) (Fujifilm, Saitama, Japan) was developed as a new type of image-enhanced endoscopy [92]; it was also enhanced with a "blue mode" ("BM") modality. This system is now embedded into the Rapid reading software. Other software (such as augmented live-body image color spectrum enhancement [ALICE]) is also available and embedded into other capsule endoscopy platforms (MiroView; Intromedic, Seoul, Korea) [93]. The majority of the evidence in the literature refers to the clinical validity of FICE in capsule endoscopy. Several studies have evaluated the role of image-enhanced capsule endoscopy in improving the characterization (i. e., visualization and/or delineation) of lesions [94-101]. The impact of FICE on lesion detection rate has been extensively evaluated [94-99, $102-109]$. A recent meta-analysis of pooled results of 13 studies (10 fo- cused on lesion detection and 3 on lesion delineation) explored the possible role of different FICE settings. The authors evaluated separately the three available FICE settings for each subtype of small-bowel lesion (vascular, inflammatory, and protruding). Interestingly, in this meta-analysis all three FICE modes failed to show any significant improvement either in detection or delineation of any subtype of small-bowel lesion [110].

The "blue mode" modality, alone or in conjunction with FICE, was also examined $[98-102,104,109,111]$ and the results for this adjunctive modality are heterogeneous. Recent studies failed to show any benefit of blue mode over conventional white light capsule endoscopy in delineating small-bowel lesions [104]. With regard to lesion detection [94, 102-104, $108,112]$, blue mode was shown to improve the detection rate in one study [109], while no difference in detection rate was observed in another study [104]. With regard to ALICE, the few data available do not allow recommendations to be made.

\subsection{Reporting}

\section{RECOMMENDATION}

ESGE recognizes that data are scarce on the type of information to be included in the SBCE report. ESGE suggests that standardized scores, when applicable, should be used to describe relevant findings. Lesion location should also be reported by means of a relevant transit-time index.

Weak recommendation, low quality evidence.

There is little evidence on which to base recommendations for what should be included in the SBCE report. However there is clearly information that should be included in every endoscopy report (i.e., patient name, demographic and contact details, referrer details, procedure indications, brief history of previous investigations, and relevant medical details). The SBCE report should also include: (a) procedure-related data (some of which is provided by the relevant proprietary software, i.e., gastric transit time, small-bowel transit time, and overall recording time); (b) bowel preparation used, if any; (c) quality of bowel preparation (possibly evaluated using a published grading scale [113] even if, as currently, robust validated scales are lacking and computer automated systems are still under evaluation); (d) completion/extent of examination; (e) clinical findings; and (f) advice.

Considering the intrinsic limitations of SBCE, the report should include (when applicable):

- estimated lesion size and estimated location;

- objective reporting of any visualized inflammatory changes, by means of the Lewis score or Capsule Endoscopy Crohn's Disease Activity Index CECDAI) [114, 115], as appropriate;

- an accurate description by means of the Smooth, Protruding lesion Index on Capsule Endoscopy (SPICE) score, and/or the Shyung score $[116,117]$ (for protruding lesions which may either represent neoplasms or innocuous mucosal bulges); and 
- the clinical relevance of the findings (i. e., the predicted significance of observed lesions, especially in those referred with suspected small-bowel bleeding) [118].

An estimate of lesion location, based on a transit-time index (e.g., the time from the pylorus to the lesion, divided by the time from the pylorus to the ileocecal valve [119]), should always be included for every identified lesion in order to facilitate selection of the appropriate approach for a subsequent DAE procedure (i.e., antegrade or retrograde route) $[119,120]$; see also section 4.5). The standardized scores, along with the estimated lesion location, are helpful in shortening the SBCE report, thus avoiding long, arbitrary, and sometimes ambiguous descriptions. Nevertheless the reader must summarize the findings in a clear and clinically relevant manner that allows the referring physician to plan the patient's future therapeutic/diagnostic management.

\subsection{Complication rates and prevention of complications (see also section 3.11: Use of the patency capsule)}

\section{RECOMMENDATION}

ESGE recommends observation in cases of asymptomatic capsule retention.

Strong recommendation, moderate quality evidence. When clinically indicated (e.g., in patients with IBD), a targeted treatment with steroids should be considered to facilitate capsule egestion.

Strong recommendation, low quality evidence.

\section{RECOMMENDATION}

In cases where capsule retrieval is indicated, ESGE recommends the use of device-assisted enteroscopy (DAE) as the method of choice. When clinically indicated or when DAE is unsuccessful, surgical intervention is indicated to retrieve the capsule and/or to treat the underlying disease

Strong recommendation, moderate quality evidence.

\section{RECOMMENDATION}

ESGE recommends the use of endoscopic capsule placement in patients with a suspected or established nonobstructive swallowing disorder, in order to prevent capsule aspiration.

Strong recommendation, low quality evidence.

It has been well established that certain underlying conditions predispose to capsule retention. A recently published meta-analysis showed that the capsule retention rate was $2.1 \%$ for patients with suspected small-bowel bleeding $(95 \% \mathrm{Cl}$ $1.5 \%-2.8 \%)$ and $2.2 \%(95 \% \mathrm{Cl} 0.9 \%-5.0 \%)$ for those having evaluation because of abdominal pain and/or diarrhea. The retention rate for patients with suspected IBD was $3.6 \%(95 \% \mathrm{Cl}$ $1.7 \%-8.6 \%)$ but that for patients with established IBD was $8.2 \%(95 \% \mathrm{Cl} 6.0 \%-11.0 \%)$ [121]. Capsule retention is usually asymptomatic $[122,123]$ and the capsule can remain in the small bowel without symptoms for several months or even be naturally egested during subsequent follow-up [122 - 134]. In a recent study, only 2 out of 104 capsule retentions (1.9\%) developed into a symptomatic bowel obstruction [121,123]. Thus, unless malignancy is strongly suspected, conservative observation is a justified therapeutic option for management of capsule retention in the majority of cases. During this period, targeted treatment with medications (including corticosteroids as appropriate), may promote capsule egestion in up to $20 \%-30 \%$ of patients with capsule retention $[119,128,129]$.

When capsule retrieval is required, both DAE and surgery appear to be viable alternatives. In early capsule studies surgery was the treatment of choice, even in asymptomatic cases $[123,128,130-133]$. In current practice, the increasing availability of DAE has reduced the need for surgery. If a capsule is retained in the small bowel and early surgical management is not required, DAE has proven to be extremely effective ( $90 \%-$ $100 \%$ of cases) in achieving capsule retrieval [135-137]. Nonetheless, surgical intervention remains the first choice in all cases in which investigations unequivocally suggest the presence of a neoplastic disease. In these cases surgery is primarily aimed at treating the small-bowel disease, simultaneously allowing capsule retrieval.

Other complications reported in the literature such as bowel perforation and capsule disintegration are anecdotal and have only been published as case reports [123-126]. Possible complications that were postulated at the time of introduction of capsule endoscopy into clinical practice (e.g. retention of capsules within jejunal or colonic diverticula, interaction with pacemakers, etc.) were shown to be very infrequent and/or without clinically relevant consequences [138]. Conversely, capsule aspiration has emerged as a potentially serious albeit infrequent adverse event [139]. A recent systematic literature review reported that the overall aspiration rate is $0.1 \%$ [140]. Although capsule endoscopy has been demonstrated to be safe in elderly patients, most capsule tracheobronchial aspirations (around $90 \%$ ) have been reported in this subset of patients [134, $138-140]$. Hitherto undiagnosed silent swallowing disorders may be the underlying cause of these findings. Therefore, a complete clinical history before capsule administration is highly recommended; special attention should be paid to identifying potential swallowing dysfunction in elderly patients. In the situation where a patient has swallowing disorders or difficulties, the physician should place the capsule endoscopically into the duodenum (preferably with a dedicated capsule endoscopy delivery device or, if this is unavailable, through other accessories, such as a Roth Net). Such techniques have been demonstrated to be feasible and safe [141 - 143]. 


\subsection{Use of the patency capsule}

\section{RECOMMENDATION}

ESGE recommends taking a complete medical history (e.g., previous abdominal surgery, prescribed and overthe-counter medications taken, obstructive symptoms, etc.) in all patients undergoing SBCE.

Strong recommendation, low quality evidence.

\section{RECOMMENDATION}

ESGE does not recommend offering a patency capsule procedure indiscriminately to all patients undergoing capsule endoscopy.

Strong recommendation, low quality evidence.

ESGE recommends that a patency capsule procedure should be offered to patients at increased risk of capsule retention.

Strong recommendation, moderate quality evidence.

As noted above, the overall capsule retention rate is low and is related to clinical indication [121]. Therefore the routine use of a technique aimed at preventing capsule retention is not necessary in every patient referred for SBCE. However, the presence of a combination of symptoms of abdominal pain, abdominal distension, and nausea/vomiting before capsule endoscopy has been shown to be associated with a significantly higher rate of capsule retention $[122,130,144,145]$. Furthermore, previous small-bowel resection, abdominal/pelvic radiation therapy, and chronic use of high dose nonsteroidal anti-inflammatory drugs (NSAIDs) have all been shown to increase the risk of capsule retention $[131,132,145-148]$. Therefore, before performing capsule endoscopy it is crucial to carefully assess the patient's past medical history in order to identify those requiring a dedicated preliminary work-up aimed at preventing capsule retention.

In this setting, small-bowel follow-through (SBFT) and abdominal computed tomography (CT) are unreliable whereas patency capsule testing and dedicated small-bowel cross-sectional imaging techniques have both been found to be effective [149]. A recently published meta-analysis (including 5 studies and 203 patients) confirmed the accuracy of patency capsule testing, with a sensitivity of $97 \%(95 \% \mathrm{Cl} 93 \%-99 \%)$, a specificity of $83 \%(95 \% \mathrm{Cl} 65 \%-94 \%)$ and an area under the receiver operating characteristic (ROC) of 0.9557 [150]. Unfortunately, studies comparing patency capsule testing and dedicated small-bowel cross-sectional imaging techniques in patients at increased risk for capsule retention are limited, and the results have been conflicting. Yadav et al. showed a substantial equivalence between use of the patency capsule and dedicated crosssectional imaging techniques [151], whereas a multicenter Italian study showed that the retention rate was significantly lower $(0.7 \%)$ in high risk patients with negative patency capsule results than in those with negative results from dedicated prior small-bowel cross-sectional imaging (8.3\%) [152]. Furthermore the patency capsule procedure does not require significant exposure to ionizing radiation; it is also user-friendly and has a very high negative predictive value. On the other hand, some cases of obstruction due to patency capsule ingestion have been reported [153].

\section{Statements and recommendations on device-assisted enteroscopy (DAE)}

\subsection{Commercially available devices}

The commercially available enteroscopes and dedicated overtubes for DAE, are listed in Table 2 (see Appendix e3, onlineonly Supplementary material).

\subsection{Preparation}

\section{RECOMMENDATION}

ESGE recommends 8-12 hours' fasting from solid food and also 4-6 hours' fasting from liquids before the procedure, for patients undergoing antegrade DAE. For patients undergoing retrograde DAE, ESGE recommends the optimal colonoscopy preparation regimen.

Strong recommendation, moderate quality evidence.

As with other endoscopic procedures [154], the quality of bowel preparation and absence of residue is paramount for lesion detection at DAE. Additionally, food residue or fecal debris can hinder the DAE procedure through excessive friction between the enteroscope and the overtube.

There are no comparative studies on preparation for antegrade (peroral) DAE. Moreover, all authors report a similar regimen, which is based on small-bowel physiology [155-157]: an 8-12-hour fast from solid food and a 4-6-hour fast from liquids is usually recommended [158-161]. For retrograde (peranal) DAE, an optimal colonoscopy preparation regimen [158161 ] is generally recommended. Its schedule differs from study to study. Since suboptimal colonic cleansing can significantly hamper DAE progression and prevent ileocecal valve intubation, ESGE recommends the state-of-the-art colonoscopy preparation regimen $[162,163]$.

In the presence of an underlying clinical condition, which may increase the risk of luminal residue (e.g. in the context of small-bowel stenosis or obstructive symptoms), a more prolonged fast and the use of bowel preparation should be considered even in patients undergoing antegrade DAE. In these cases, the optimal preparation schedule should be decided upon on a case-by-case basis, taking into account several factors such as procedure timing, clinical indication, sedation regimen, expected lesion location, enteroscope insertion route etc. Urgent DAE for large-volume bleeding should be performed via the antegrade route (see also section 4.5$)[164,165]$ and in this context, the abovementioned recommendations for scheduled antegrade DAE should also be followed. 


\subsection{Setting}

\section{RECOMMENDATION}

ESGE recommends performing diagnostic DAE as a daycase procedure in patients without significant underlying co-morbidities; in patients with co-morbidities and/or those undergoing a therapeutic procedure, an inpatient stay is recommended.

Strong recommendation, low quality evidence.

The choice between different settings also depends on sedation protocols.

Strong recommendation, low quality evidence.

The choice between inpatient and day-case setting mostly depends on the need for periprocedural clinical monitoring. Vigilant clinical monitoring is mandatory whenever there is an increased risk of adverse events. Published data on DAE adverse events mainly come from DBE studies. The overall DAE-related complication rate is around $1 \%$ [166-172]. The complication rate of diagnostic procedures is up to $0.8 \%$ [166-171], while that of therapeutic procedures may be as high as $8 \%$ [173175]. The most common complications of DAE are perforation, bleeding, and pancreatitis. Bleeding and perforation are more commonly associated with therapeutic interventions, such as polypectomy (up to $10 \%$, when large polyps are resected en bloc) [175] and dilation of strictures (up to $8 \%$ ) [173]. Pancreatitis has been reported to occur in $0.3 \%$ of DAE procedures (in the large majority of cases during antegrade DAE). The mechanism of DAE-related acute pancreatitis appears to be possibly related to ischemic/traumatic injury to the pancreas during push-and-pull maneuvers [171]. Post-DAE acute pancreatitis has been found to be associated with the duration of the procedure and the depth of endoscope insertion [176-180]. The risk of pancreatitis may be reduced by a careful, atraumatic technique, minimizing mechanical stress and avoiding inflation of balloons within the proximal duodenum [175]. Other preventive measures are highlighted in section 4.10 of this document.

Although, as detailed above, procedure-related complications have been reported in patients undergoing high risk endoscopic therapy (e.g., balloon dilation, resection of large polyp, and stenting), severe complications (i.e., perforation) have also been reported in patients receiving hemostatic treatments (e.g., argon plasma coagulation), which are generally considered to be low risk endoscopic therapies in other gastrointestinal segments. Therefore, for all patients undergoing therapeutic procedures, the ESGE recommends prolonged post-procedure patient monitoring; this is best performed in the inpatient setting. Patients who have significant co-morbidities are at a higher risk of adverse events (mostly sedationrelated complications; see section 4.4) and should generally also be offered inpatient monitoring post-DAE.

Adverse event rates for the different types of DAE have been shown to be similar [181-187], regardless of patient age [188, 189]. Therefore, patient age and type of DAE equipment used should not influence the choice of procedure setting. Although the rate of acute pancreatitis is higher in patients undergoing antegrade examination $[166,167]$, the different insertion route alone (antegrade or retrograde) should not influence the choice of setting.

These recommendations should be locally implemented, taking into account local organizational models and reimbursement policies.

\subsection{Sedation}

\section{RECOMMENDATION}

ESGE recommends adequate, safe sedation for DAE. Strong recommendation, low quality evidence.

ESGE suggests that conscious sedation, deep sedation, and general anesthesia are all acceptable alternatives: the choice between them should be governed by procedure complexity, clinical factors, and local organizational protocols.

Weak recommendation, low quality evidence.

DAE procedures are lengthy, and require adequate smallbowel distension for effective lesion visualization and treatment. Furthermore, both the enteroscope and overtube need to be advanced and withdrawn repeatedly over the course of the procedure; this manipulation of the small bowel, its mesentery, and adjacent viscera may cause discomfort/pain. This may impact on the patient's compliance and the overall effectiveness of the procedure. In addition, patient movement during DAE can make the procedure more technically challenging. Adequate, safe sedation during DAE is therefore highly advantageous. Nevertheless, sedation safety should remain paramount, since sedation-related complications have been reported in up to $0.5 \%$ of the 2245 patients collected in a prospective German database [168].

A wide range of sedation protocols for DAE has been described in the literature, and all of them have been reported to be safe. Several large recently published case series [190 - 194], including both retrograde and antegrade procedures, showed that enteroscopy may be safely performed under combined benzodiazepine and opiate delivered sedation, even in patients with relevant co-morbidities. Nevertheless, these are mostly retrospective case series, not focused on sedation-related complications. Therefore, as recently suggested [195], the sedation-related complication rate might be underestimated in patients undergoing DAE with conscious sedation.

The retrospective study by Zubek et al. [196] showed that, in patients undergoing DBE, general anesthesia with endotracheal intubation prevents the risk of aspiration and can also be safely applied. With adequate training, sedation-related adverse events such as hypotension, desaturation and apnea can be rapidly and effectively managed. In 2014 Sethi et al. [197] showed that, for patients undergoing single-balloon enteroscopy, monitored anesthesia care (MAC) without endotracheal intubation is safe; the same applies to nurse-administered intermittent deep sedation with propofol for advanced endoscopies 
(including DBE) [198]. Recently, Kawano et al. [199] proposed a new sedation regimen for antegrade DBE procedures, based on target-controlled infusion anesthesia with propofol, plus an intravenous bolus of pentazocine when needed, under bispectral (BIS) monitoring. In this study no patient experienced any serious adverse event and the sedation protocol was rated as satisfactory by all patients and by $80 \%$ of endoscopists.

To the best of our knowledge, there is only one comparative study focused on DAE sedation [200]. This prospective nonrandomized case series compares gastroenterologist-guided nurse-administered conscious sedation (benzodiazepine-opiate combination) with anesthetist-delivered sedation (MAC or general anesthesia), in patients undergoing spiral enteroscopy. No differences in either the procedural outcome or complication rate were encountered, leading the authors to favor the use of conscious sedation. Nevertheless, because of the lack of randomization (the American Society of Anesthesiologists [ASA] score [201] as well as the prevalence of intestinal adhesions being different between the two groups), the conclusions reached remain questionable.

Unfortunately, there are few available data regarding the impact of sedation on DAE success or estimated small-bowel depth of insertion. Murino et al. [202], by analyzing the factors influencing the depth of insertion during DBE, showed that it was not related to the type of sedation used (conscious sedation or general anesthesia). Tanaka et al. [203] reported that retrograde DBE could be effectively performed under conscious sedation, whereas the antegrade route required deeper sedation. Interestingly, Sidhu et al. confirmed this observation only in young patients (mean age 54 years, range $18-70$ ), while in older patients undergoing DBE (mean age 77 years, range 70 83 ) the mean dosage of sedatives (benzodiazepine and opiate) was comparable, regardless of the insertion route [189]. However, to date, no large randomized prospective studies have evaluated DAE success according to the type of sedation/anesthesia used.

Notwithstanding this limitation, currently available data suggest that the sedation regimen does not appear to generate differences in small-bowel insertion depth and overall DAE procedure success rates. Not enough data currently exist that relate to different DAE techniques or to different insertion routes according to the sedation regimen. Similarly, specific data about patient satisfaction according to sedation or different devices are lacking. Therefore, at the present time, a specific sedation regimen cannot be recommended. As for other advanced endoscopic procedures, the choice of sedation regimen would depend on patient-related and other clinical factors (e.g., co-morbidities, ASA score, ongoing therapies etc.), on technical issues (e.g., expected procedure duration, planned endoscopic therapy etc.), and also on local organizational protocols. Therefore this choice often involves different specialists (e.g., gastroenterologists, anesthesiologists, nurses etc.), and may influence several practical issues such as the setting (daycase procedure vs. inpatient procedure)

\subsection{Choice of insertion route (antegrade vs. retrograde)}

\section{RECOMMENDATION}

ESGE recommends that the findings of previous diagnostic investigations should guide the choice of insertion route.

Strong recommendation, moderate quality evidence.

\section{RECOMMENDATION}

If the location of the small-bowel lesion is unknown or uncertain, ESGE recommends that the antegrade route should be generally preferred.

Strong recommendation, low quality evidence.

\section{RECOMMENDATION}

In the setting of massive overt bleeding, ESGE recommends an initial antegrade approach.

Strong recommendation, low quality evidence.

\section{RECOMMENDATION}

ESGE recommends against performing antegrade and retrograde DAEs in the same session.

Strong recommendation, low quality evidence.

DAE is usually preceded by less invasive investigations, such as SBCE or dedicated small-bowel cross-sectional imaging (i. e., computed tomographic or magnetic resonance enterography or enteroclysis). These investigations may allow estimation of the location of a small-bowel lesion and should be used to guide the insertion route for DAE.

In 2006 Gay et al. [204] performed a study in which a SBCE transit time-based index was used to decide the DBE insertion route. In this study, a retrograde DBE was performed if the capsule transit time from ingestion to lesion detection was $>75 \%$ of the total time from ingestion to cecal visualization. The authors found that the positive and the negative predictive values of this SBCE transit time-based index were $94.7 \%$ and $96.7 \%$, respectively. Therefore, it appeared to reliably predict the correct DAE route of approach; only about $12 \%$ of cases required a second DAE via the alternative route.

Subsequently, Li et al. proposed a time-based location index, defined as the time from the pylorus to the lesion as a percentage of the time from the pylorus to the ileocecal valve [119]. In a study of 60 patients who underwent both SBCE and DAE, a cutoff of $60 \%$ was highly accurate in guiding the choice of DAE insertion route. These results have been recently confirmed by Mandaliya et al. [205]. 
In a retrospective study of 250 DAE procedures performed for several clinical indications, Sanaka et al. [206] demonstrated that the antegrade route was associated with a higher diagnostic yield than the retrograde route. This was also shown by Akyuz et al. [207], who found that the detection of significant small-bowel pathology was higher for the antegrade route in the subgroup of patients with small-bowel bleeding. This observation, namely that pathological lesions in the context of patients with small-bowel bleeding were identified more frequently in the proximal small bowel, has also been shown in several other studies $[161,206-211]$. These data support the antegrade approach route when previous pre-DAE investigations are unable to provide data about lesion location, at least in patients referred for suspected small-bowel bleeding. In contrast, in the context of Crohn's disease or neuroendocrine tumors, a retrograde approach should be considered first, given the propensity of these conditions to involve the distal small bowel [212, 213].

In the setting of massive overt gastrointestinal bleeding, the antegrade route is generally preferred for both technical and clinical reasons. From a technical standpoint, if a retrograde DAE is performed in this setting, blood and clots flowing towards the enteroscope decrease visibility, and may cause further hindrance through excessive friction between the enteroscope and the overtube; transportation of blood and clots proximally by the procedure itself may also hamper identification of the actual bleeding point. In addition, as mentioned above, the antegrade route has been shown to have a higher diagnostic yield in the context of small-bowel bleeding [164, 170].

When the target lesion is not reached, the deepest point of insertion into the small bowel should always be marked with a submucosal tattoo. A further DAE, performed via the opposite route, can then be attempted in order to reach the target lesion or the tattoo $[168,174,214]$. A retrospective analysis of 290 DBE procedures by Teshima et al. [215] demonstrated an increased insertion depth for the retrograde approach if this was performed on a separate occasion, rather than immediately following antegrade insertion, implying that achievement of panenteroscopy may be more likely if antegrade and retrograde approaches are performed on separate days. Therefore, a combined antegrade and retrograde approach during the same session is not generally recommended.

\subsection{Estimating the insertion depth}

\section{RECOMMENDATION}

ESGE recommends that, for balloon-assisted enteroscopy (i.e., SBE and DBE), small-bowel insertion depth should be estimated by counting net advancement of the enteroscope during the insertion phase, with confirmation of this estimate during withdrawal.

Strong recommendation, low quality evidence.
RECOMMENDATION

ESGE recommends that, for spiral enteroscopy, insertion depth should be estimated during withdrawal.

Strong recommendation, moderate quality evidence.

\section{RECOMMENDATION}

Since the calculated insertion depth is only a rough estimate, the ESGE recommends placing a tattoo to mark the identified lesion and/or the deepest point of insertion.

Strong recommendation, low quality evidence.

The method for measuring insertion depth was first described for DBE $[216,217]$. During a DBE procedure, insertion depth of the enteroscope into the small bowel should be estimated by recording, on one standardized form, the net advancement of the endoscope for each push-and-pull maneuver; these net estimates are then added to obtain the overall estimated depth of insertion. This method was initially developed using an ex vivo animal model [216] and was also eventually tested on in vivo porcine models [218]. In the latter study the insertion depth was estimated during insertion and withdrawal. Although both these estimates were similar to the autopsy reference standard, the estimates obtained during the insertion phase were more accurate. Two other alternative methods have subsequently been proposed: one is based on counting the folds during withdrawal [219], while the other is based on measurement of overtube advancement [220]. However, both these alternatives have some limitations: the first method is not easily applicable in clinical practice whereas the second is based on the hypothesis that $5 \mathrm{~cm}$ of overtube advancement invariably correspond to $40 \mathrm{~cm}$ of enteroscope advancement. Unfortunately, the small bowel is not always plicated onto the overtube in the same way, it is not continuously filled with the same volume of insufflating gas, and not all small-bowel segments can be stretched in the same way. Furthermore, the overtube balloon can slip back in the presence of adhesions or tight angulations.

Since all balloon-assisted enteroscopy techniques are based on the push-and-pull principle, the method for insertion depth estimation proposed for DBE has also been applied to SBE. Nevertheless, there are some specific SBE-related issues that can make insertion depth estimation even more challenging. During SBE, the enteroscope tip angulation used for the pull maneuver [221] partially obstructs the view and this may make estimation of depth more challenging. Although this potential limitation could be overcome by the use of suction instead of tip angulation, small-bowel slippage from the enteroscope tip and/or overtube during pullback may make estimation of insertion more difficult, particularly when the enteroscope is located deep within the small bowel or in cases of technically challenging anatomy. 
In contrast to BAE, in which insertion depth is estimated in a step-by-step manner during intubation, at spiral enteroscopy small-bowel depth is estimated on withdrawal [222]; the endoscopist attempts to estimate the length of small bowel "released" from the overtube as it is gradually withdrawn.

Regardless of the type of DAE used, enteroscopists should undergo specific training, ideally facilitated by dedicated small-bowel models [222], and estimated insertion depth should be documented on one structured standard form [222]. Furthermore, it should be borne in mind that insertion depth is frequently only a rough estimate and, even if reliable, should not obviate the requirement for tattoo-based marking of lesion location and/or deepest point of insertion.

Several studies have compared the different DAE techniques in order to determine which facilitates a more extensive evaluation of the small bowel. Unfortunately, most of these studies are retrospective, nonrandomized, single-center, and performed by expert endoscopists only. Because of these methodological limitations, combined with the subjective nature of estimation of small-bowel insertion, these studies have shown conflicting results. There are three randomized controlled studies comparing SBE with DBE [219, 223, 224]. Two of these [219, 223] reported comparable insertion depths, whereas the third one [224] showed that DBE was associated with deeper insertion. In light of these inconsistencies, two meta-analyses of RCTs have been performed [225, 226]. Both these meta-analyses showed that DBE and SBE were similar in terms of estimated insertion depth, diagnostic yield, therapeutic yield, and complications. This result is in keeping with that of a previous systematic review on the same topic (which included 68 studies that were mostly retrospective studies and case series) [227]. When antegrade DBE was compared with spiral enteroscopy, two back-to-back studies $[228,229]$ consistently showed that DBE allowed deeper insertion.

Complete enteroscopy has also been proposed as a metric for the comparison of different DAE techniques. Although prospective RCTs comparing DBE and SBE [214, 223, 224, 230], reported conflicting results, both of the recently published metaanalyses confirmed that the total enteroscopy rate was significantly higher for DBE when compared with SBE $[225,226]$. Nevertheless, although total enteroscopy remains a useful achievement, the diagnostic and therapeutic yield of DBE and SBE remain similar. Furthermore, although a negative complete small-bowel enteroscopy is clinically reassuring, diagnosis and therapy can often be accomplished in a single session and the achievement of complete enteroscopy is only required in a minority of patients. At present therefore, DBE and SBE (the two modalities for which there is substantial evidence), appear similarly suitable for routine clinical practice; less data are available for spiral enteroscopy. In addition, new enteroscopes are under evaluation (e.g., the automatic spiral enteroscope, new DBE prototypes), which may increase our capability for inspecting the entire small bowel in a single session, decrease operative time, and facilitate therapeutic maneuvers in the future.

What emerges clearly from all current studies, regardless of specific DAE technique, is that both the estimated depth of insertion and complete enteroscopy rate increase with experi- ence [4,216,231-234]. Appropriate training as well as high procedure volume are relevant factors for mastering DAE and for ensuring technical success and clinical effectiveness.

\subsection{Use of fluoroscopy}

\section{RECOMMENDATION}

ESGE suggests that routine use of fluoroscopy is not essential. Nevertheless, it may be useful in particular circumstances (e.g. during the learning curve, in patients with altered anatomy, or in those with small-bowel strictures, etc).

Weak recommendation, low quality evidence.

Only one prospective randomized study evaluated the impact of the routine use of fluoroscopy in antegrade DBE [235]. In this study, fluoroscopic control had no influence on insertion depth, or procedure time. However, it should be borne in mind that in this study a highly experienced endoscopist performed all procedures and this fact may have had a bearing on the result.

In large retrospective case series, fluoroscopy was mainly applied on-demand, depending on the endoscopist's experience and the patient's small-bowel anatomy [234, 235]. Fluoroscopy is reported to be particularly useful at the beginning of the learning curve and in the presence of post-surgical adhesions $[234,236]$. Although the majority of studies were performed with DBE, we can, in all probability, extend the present recommendations about fluoroscopy to SBE because of the similarities in the endoscopic technique [221]. As far as spiral enteroscopy is concerned, there are currently no data or studies focused on this specific topic.

In the context of suspected small-bowel strictures (e.g., in patients with Crohn's disease), the use of fluoroscopy is recommended particularly to assess the complexity of any stenosis (e.g., length, angulation, and caliber), through the use of radiological contrast media [237]. The use of fluoroscopic control is mandatory for effective and safe dilation of small-bowel strictures (see also section 4.10).

\subsection{Use of carbon dioxide for insufflation}

\section{RECOMMENDATION}

ESGE recommends carbon dioxide $\left(\mathrm{CO}_{2}\right)$ for insufflation in all patients undergoing DAE.

Strong recommendation, high quality evidence.

DAE procedures usually take over 1 hour to complete and require insufflation with large volumes of gas [238]. Whereas insufflation using air may lead to significant small-bowel distension during and after the procedure, $\mathrm{CO}_{2}$ is rapidly absorbed from the gastrointestinal tract and as a result leads to less distension. Several RCTs have evaluated the use of $\mathrm{CO}_{2}$ in DAE and 
its impact on patient comfort and insertion depth [239-242]. A systematic review with meta-analysis by Nishizawa et al. [243] has recently analyzed 4 RCTs (2 on DBE and 2 on SBE; 461 patients overall, 235 randomized to undergo enteroscopy with air and 226 with $\mathrm{CO}_{2}$ insufflation) that aimed to evaluate the impact of $\mathrm{CO}_{2}$ in DAE procedures. When compared with air, use of $\mathrm{CO}_{2}$ insufflation significantly increased the insertion depth for antegrade enteroscopy, but not for the retrograde approach. The use of $\mathrm{CO}_{2}$ insufflation significantly reduced post-procedure abdominal pain in both retrograde and antegrade DAE. Interestingly, Lenz et al. [241] reported that in the subgroup of patients with a history of abdominal surgery, $\mathrm{CO}_{2}$ insufflation appeared to be particularly beneficial, since the insertion depth for antegrade procedures performed in these cases was significantly greater when $\mathrm{CO}_{2}$ was used $(\sim 60 \mathrm{~cm}$ deeper than when air was used as the insufflating gas).

Various studies [9,244-248] have shown that the use of $\mathrm{CO}_{2}$ is safe, even during lengthy endoscopic procedures (including DAE $[9,239-243,248]$ ) and that standard patient monitoring is sufficient for its use.

Based on findings from studies on water-assisted colonoscopy [249-251], some authors have recently suggested the use of water, instead of $\mathrm{CO}_{2}$, for luminal distension at DAE. Liang et al. [252] recently randomly allocated 110 consecutive patients to undertake SBE with standard $\mathrm{CO}_{2}$ insufflation or with the water-exchange technique. They found that the water-exchange method improved complete enteroscopy rates and small-bowel insertion depths during SBE. Adverse events for water-exchange enteroscopy were similar to those observed with the $\mathrm{CO}_{2}$ insufflation method. These preliminary results warrant further research.

\subsection{How to optimize evaluation of the small-bowel mucosa}

\section{RECOMMENDATION}

ESGE recommends inspecting the small-bowel mucosa with adequate insufflation, preferably during the withdrawal phase.

Strong recommendation, low quality evidence.

There are no studies comparing the detection rate of smallbowel lesions during enteroscope insertion and withdrawal. Minimal insufflation during the insertion phase enables smallbowel plication onto the overtube and this in turn facilitates deeper insertion. Suboptimal distension, however, may hinder the identification of mucosal lesions, especially when these are small or located between nondistended folds. Therefore, the small-bowel mucosa should be assessed with adequate luminal distension, mainly during the withdrawal phase.

As with other endoscopic procedures [253], the use of a dedicated, short, transparent plastic cap (distal attachment) has been proposed by experts to improve visualization of small lesions behind folds, and also to ease therapeutic procedures by exposing the lesion [254]. Dufault et al. [255] have recently reported a case series of 36 patients in which the routine use of a transparent cap allowed a successful terminal ileal intubation during retrograde SBE in $97 \%$ of cases.

Misra et al. [256] showed that the administration of the antispasmodic agent hyoscine- $\mathrm{N}$-butylbromide facilitates terminal ileal intubation and visualization during colonoscopy. However, to date, there are no studies evaluating the effect of the administration of antispasmodic agents on DAE lesion detection rates.

\subsection{Therapeutic maneuvers}

\section{RECOMMENDATION}

ESGE recommends that, for small-bowel pathology, DAE should be the preferred option for investigation and therapeutic intervention before more invasive modalities, unless otherwise clinically indicated.

Strong recommendation, low quality evidence.

\section{RECOMMENDATION}

ESGE recommends that all endoscopic therapeutic procedures can be undertaken at the time of DAE.

Strong recommendation, moderate quality evidence.

\section{RECOMMENDATION}

ESGE recommends that, when therapeutic interventions are performed, additional specific safety measures are needed to prevent complications.

Strong recommendation, high quality evidence.

\section{RECOMMENDATION}

ESGE suggests that endoscopic therapy during DAE should generally be performed during the withdrawal phase of the procedure.

Weak recommendation, low quality evidence.

DAE facilitates all endotherapeutic modalities, including hemostatic treatments (by argon plasma coagulation [APC], injection therapy, and clip placement), resection of polypoid lesions, dilation of strictures, stent placement, retrieval of foreign bodies, direct insertion of jejunal feeding tubes (direct percutaneous endoscopic jejunostomy [DPEJ]), and endoscopic retrograde cholangiopancreatography (ERCP) post gastric surgery $[160,161,174,217,237,257-269]$.

Given the position of the lesions identified and treated by DAE (deep within the small bowel), surgical intervention used to be the only viable therapeutic option before DAE was introduced into clinical practice. DAE endotherapy currently offers a safe and effective alternative to major surgery (see also section 4.3) and often represents the preferred option for treatment of small-bowel pathology. However, especially when deal- 
ing with patients with complex small-bowel diseases, the evaluation of treatment options and treatment planning are collaborative processes: these patients are best managed with a multidisciplinary approach involving different health care professionals such as gastroenterologists, radiologists, surgeons, anesthesiologists, and pathologists.

Therapeutic interventions during DAE are however technically demanding, given the long ( $2 \mathrm{~m}$ ) enteroscope. Also, therapy by DAE is often made more challenging by atypical smallbowel looping and a relatively unstable enteroscope position [270]. In addition, given that the small-bowel wall is particularly thin (only up to $3 \mathrm{~mm}$ in thickness) [271], one should be particularly careful to avoid perforation when applying endotherapy within the small bowel. Although there are no published studies comparing different endotherapies, experts recommend particular precautions when undertaking these within the small bowel. These safety recommendations, depending on the therapeutic modality, are as follows:

- APC of vascular lesions. Keeping in mind both the reduced small-bowel wall thickness and manufacturers' recommendations, low wattage settings should be used; pre-injection of saline into the submucosa before application of APC should also be performed, particularly for large (>0.5-0.7-cm) vascular lesions.

- Endoscopic resection of mucosal lesions. In order to reduce the risk of perforation and bleeding, the base of the stalk of pedunculated lesions may be injected with a dilute solution of adrenaline in normal saline (1 in 100 000). Sessile lesions, as well as large lesions, would be best resected piecemeal after submucosal injection. However, because of the small diameter of the small-bowel lumen, injection of a large volume of lifting solution should be avoided. (For example, $1-2 \mathrm{~mL}$ at the base of pedunculated polyps or $5-10 \mathrm{~mL}$ for flat lesions are usually enough to ensure a safe resection, leaving enough space for an easy and effective snare placement.) For the resection of hamartomatous pedunculated polyps (e.g. in the setting of Peutz-Jeghers syndrome), the stalk should be resected close to the polyp head, in order to reduce the risk of perforation and to allow adequate postpolypectomy clip placement to the polyp stalk stump after resection $[272,273]$.

- Dilation of small-bowel strictures. Prior to endoscopic balloon dilation (EBD), a thorough evaluation of the number, location, characteristics, and length of the strictures should be performed by dedicated small-bowel diagnostic imaging $[173,266,274,275]$. Short strictures $(<5 \mathrm{~cm})$ are more likely to have a favorable long-term response than longer ones $[173,266,276]$. Active inflammation, such as deep ulceration within the stricture, is associated with a higher risk of perforation and should be managed with escalation of medical therapy before EBD is reconsidered [173, 266, 274 276]. Another factor that may increase perforation risk is sharp angulation; straight strictures are therefore considered to be more appropriate for $\operatorname{EBD}[173,266]$. A throughthe-scope approach, using a clear-balloon dilation system is currently the most frequently used technique associated with favorable outcomes $[173,266]$. Gradual insufflation of the balloon with water, under direct endoscopic vision, up to a maximum diameter of $18-20 \mathrm{~mm}$ for $1-2$ minutes is the generally recognized practice $[173,266]$. Fluoroscopy may provide further characterization at the time of EBD and its use is highly recommended [173, 274, 275]. Long-term success may require repeating EBD in selected cases [266].

- Direct percutaneous endoscopic jejunostomy (DPEJ) feeding tube placement. Similarly to the placement of a percutaneous endoscopic gastrostomy tube, adequate transillumination and digital indentation are prerequisites for safety and success [267]. The use of a 21-G "seeker" needle and snaring of this to anchor the jejunal loop position during insertion of the DPEJ trocar is also considered to be an essential safety measure [267].

Although there are no published comparative studies on this subject, most experts would recommend performing endotherapy on withdrawal. Enhanced visualization of lesions for therapy on withdrawal may be achieved by partial inflation of the enteroscope balloon, since this allows straightening and gentle stretching of any plicated small-bowel folds. Small solitary lesions, such as tiny vascular lesions, which may be difficult to find again on withdrawal, would be best treated during the insertion phase of the enteroscopy.

\subsection{Reporting}

In this section, specific DAE-related data which must be included in the enteroscopy report are listed. These data, shown in Table 3 (see Appendix e3 online-only Supplementary material), do not substitute for but complete the standard endoscopy report [277-279].

\subsection{Complication rate and prevention of complications}

The spectrum and rates of complications for DAE are discussed in detail in sections 4.3 and 4.4. Information on complication prevention is reported in those sections. For complications related to therapeutic maneuvers and their prevention, please refer to section 4.10. As with patients undergoing other endoscopic procedures, a careful and detailed medical history should be taken before DAE, with particular attention to medications (e.g., antiplatelets and anticoagulants) that can potentially increase the risk of bleeding. The management of patients using such medications should be undertaken according to specific guidelines [280] in which diagnostic DAE and DAE without polypectomy is considered as a low risk procedure. 


\subsection{Patient management after examination}

\section{RECOMMENDATION}

ESGE suggests that patients may drink 1 hour after and eat 2 hours after a diagnostic enteroscopy. After therapeutic interventions, the ESGE suggests a more cautious approach as regards oral intake, depending on the type of endoscopic therapy performed and the clinical circumstances.

Weak recommendation, very low quality evidence.

\section{RECOMMENDATION}

ESGE recommends against routine testing of amylase/lipase levels after DAE procedures.

Strong recommendation, low quality evidence.

There are no studies specifically focused on post-procedure management; therefore recommendations are mostly based on expert opinion. Patients undergoing diagnostic procedures are generally managed as day-cases (see also section 4.3); once post-sedation recovery is satisfactory, patients may be allowed to drink 1 hour after and to eat a light meal 2 hours after the procedure. Because of the higher risk of potential complications, patients undergoing therapeutic intervention should be managed more cautiously and the exact timing for the commencement of oral intake should be decided on an individual patient basis, depending on the specific endoscopic therapy performed, clinical circumstances, procedure duration, and co-morbidities.

Acute pancreatitis represents a severe procedure-related complication in patients undergoing both diagnostic and therapeutic DAE (see also section 4.3). Early recognition of this potential complication may impact on the final outcome. Several studies [175-179, $281-285]$ have shown that although an increase in the amylase and/or lipase levels can be documented in up to $30 \%-40 \%$ of DAE procedures, acute pancreatitis occurs only in $0.3 \%$ of patients. Therefore, measuring these enzymes routinely after DAE could potentially lead to further unnecessary investigations, prolonged clinical observation, and ultimately to an unjustifiable waste of resources. ESGE recommends that amylase and/or lipase levels should only be tested in cases of severe persistent or recurrent post-procedural abdominal pain, or as clinically indicated.

\section{Discussion}

ESGE recommendations represent a consensus of best practice based on the available evidence at the time of their writing. However, emerging technical and technological innovations may necessitate a critical appraisal of these statements in the near future. For instance, in the field of capsule endoscopy, the introduction of new capsules with software dedicated to specif- ic conditions could lead to significant changes in clinical practice. Similarly, for DAE, at the time of writing, technological innovations are expected soon. In some countries spiral overtubes are no longer available for purchase and a novel automated spiral enteroscope prototype, which may help to make the procedure easier and quicker, has recently been presented.

Furthermore, although papers relating to both SBCE and DAE are numerous, they are often characterized by important methodological limitations: RCTs and comparative and large population studies are few. Therefore, the proposed statements are often based on expert opinion rather than on methodologically robust evidence.

In the present technical review we have not addressed training-related issues. In fact, there are already specific documents on this topic, establishing thresholds regarding the achievement of competency [286-288]. Nevertheless, as frequently mentioned in the present review, we would like to emphasize the paramount importance of adequate training in order to ensure patients receive safe and effective procedures with an optimal experience and clinical outcome. In addition, given the continuous technological evolution in the field, we also wish to underline that gastroenterologists involved with enteroscopy, whether SBCE or DAE, should not only meet the requirements that grant practicing privileges where they work, but should also engage with the process of continuing professional development specifically relating to enteroscopy. ESGE recommendations are intended to be an educational instrument, to provide information which may assist gastroenterologists to provide optimal care to patients. However the proposed statements may not apply to all circumstances, and clinical considerations, as well as resource availability, organizational models, and local reimbursement policies may justify a course of action at variance to these recommendations.

\section{Disclaimer}

The legal disclaimer for ESGE Guidelines [17] applies to this Guideline.

\section{Acknowledgments}

We sincerely thank all the authors of the ESGE Clinical Guideline on video capsule endoscopy and device-assisted enteroscopy: R. Eliakim, M. Keuchel, C.J. Mulder, J. Albert, P. Baltes, F. Barbaro, C. Cellier, J.P. Charton, M. Delvaux, A. Klein, M. McAlindon, B. Rosa, G. Rowse, D.S. Sanders, J.C. Saurin, R. Sidhu, J.M. Dumonceau, C. Hassan, and I.M. Gralnek. During the editorial process of the Clinical Guideline, they discussed and raised questions about technical issues in capsule endoscopy and device-assisted enteroscopy. Therefore, the present Technical Review is mostly inspired by and based on their work.

We also thank D. Yung, A. Tortora, R. Marmo, and E. Valchou who contributed to the literature search and to the editing process.

We also thank the reviewers, J. Plevris and K. Triantafyllou: the paper was significantly improved thanks to their detailed and thorough revision process. 
Finally, we also thank Francoise Heidenreich and Martina Bertz, of the ESGE Secretariat for their invaluable help in managing all logistic and organizational issues.

\section{Competing interests}

S. Adler receives honoraria for giving seminars in capsule endoscopy, sponsored by Medtronic. E. J. Despott has received educational and travel grants and speaker's honoraria from Fujifilm, Aquilant, Diagmed, and Medtronic (2007 to present); his department has received educational and travel grants and speaker's honoraria from Olympus (2012 to present). I. Fernandez-Urien has received consultancy fees from Medtronic (2016 to 2017). A. Koulaouzidis is receiving material support for research from SynMed UK and IntroMedic (ongoing); his department is receiving material support from Aquilant/OMOM (ongoing); he received a research grant from Given Imaging (2011 to 2012). A. May receives speaker's honoraria from FALK and Fujifilm; her department is receiving research support from Fujifilm (2014 to 2018), Olympus (2014 to 2018), and Interscope (2017 to 2019). S. Panter has received sponsorship support from Diagmed and Given to attend conferences and educational events (2005 to present); his department has received research fellowship funding from Aquilant and Fuji (2013 to 2015), and support for the delivery of capsule course infrastructure costs (2005 to present); he is currently the unpaid chair of the UK capsule endoscopy users' group. G. Rahmi is giving training courses provided by Medtronic on the small-bowel capsule (2017 to 2018). C. Spada receives a consultancy fee from Medtronic. J. van Hooft's department is currently receiving research grants from Cook Medical, Boston Scientific, Olympus, and Medtronic. D. Domagk, C. Hassan, M. Pennazio, M.E. Riccioni, and E. Rondonotti have no competing interests.

\section{References}

[1] Gerson LB, Fidler JL, Cave DR et al. ACG Clinical Guideline: Diagnosis and management of small bowel bleeding. Am J Gastroenterol 2015; 110: $1265-1287$

[2] Pennazio M, Spada C, Eliakim R et al. Small-bowel capsule endoscopy and device-assisted enteroscopy for diagnosis and treatment of small-bowel disorders: European Society of Gastrointestinal Endoscopy (ESGE) Clinical Guideline. Endoscopy 2015; 47: 352 - 376

[3] Buscaglia JM, Okolo PI 3rd. Deep enteroscopy: training, indications, and the endoscopic technique. Gastrointest Endosc 2011; 73: 1023 1028

[4] ASGE Technology Committee Chauhan SS, Manfredi MA et al. Enteroscopy. Gastrointest Endosc 2015; 82: 975 - 990

[5] Ladas SD, Triantafyllou K, Spada C et al. European Society of Gastrointestinal Endoscopy (ESGE): recommendations (2009) on clinical use of video capsule endoscopy to investigate small-bowel, esophageal and colonic diseases. Endoscopy 2010; 42: 220 - 227

[6] ASGE Technology Committee Wang A, Banerjee $S$ et al. Wireless capsule endoscopy. Gastrointest Endosc 2013; 78: 805-815

[7] Yamamoto $\mathrm{H}$, Ogata $\mathrm{H}$, Matsumoto $\mathrm{T}$ et al. Clinical practice guideline for enteroscopy. Dig Endosc 2017; 29: 519- 546

[8] Shim KN, Jeon SR, Jang HJ et al. Quality indicators for small bowel capsule endoscopy. Clin Endosc 2017; 50: 148 - 160

[9] Wang WL, Wu ZH, Sun Q et al. Meta-analysis: the use of carbon dioxide insufflation vs. room air insufflation for gastrointestinal endoscopy. Aliment Pharmacol Ther 2012; 35: 1145-1154

[10] ASGE Technology Committee Barth BA, Banerjee S et al. Equipment for pediatric endoscopy. Gastrointest Endosc 2012; 76: 8-17
[11] Mishkin DS, Chuttani R, Croffie J et al. ASGE Technology Status Evaluation report: wireless capsule endoscopy. Gastrointest Endosc 2006; 63: $539-545$

[12] Viazis N, Sgouros S, Papaxoinis K et al. Bowel preparation increases the diagnostic yield of capsule endoscopy: a prospective, randomized, controlled study. Gastrointest Endosc 2004; 60: 534- 538

[13] ASGE Standards of Practice Committee Lee KK, Anderson MA et al. Modifications in endoscopic practice for pediatric patients. Gastrointest Endosc 2008; 67: 1 -9

[14] Friedlander JA, Liu QY, Sahn B et al. NASPGHAN capsule endoscopy clinical report. J Pediatr Gastroenterol Nutr 2017; 64: 485-494

[15] Arguelles-Arias F, Donat E, Fernandez-Urien I et al. Guidelines for wireless capsule endoscopy in children and adolescents: a consensus document by the SEGHNP (Spanish Society for Pediatric Gastroenterology, Hepatology and Nutrition) and SEOD (Spanish Society for Digestive Disease. Rev Esp Enferm Dig 2015; 107: 714 - 731

[16] Atkins D, Best D, Briss PA et al. Grading quality of evidence and strength of recommendations. BMJ 2004; 328: 74541490

[17] Dumonceau JM, Hassan C, Riphaus A et al. European Society of Gastrointestinal Endoscopy (ESGE) Guideline Development Policy. Endoscopy 2012; 44: 626-629

[18] Mergener K, Ponchon T, Gralnek I et al. Literature review and recommendations for clinical application of small-bowel capsule endoscopy, based on a panel discussion by international experts. Consensus statements for small-bowel capsule endoscopy, 2006/2007. Endoscopy 2007; 39: $895-909$

[19] Van Tuyl SA, den Ouden H, Stolk MF et al. Optimal preparation for video capsule endoscopy: a prospective, randomized, single-blind study. Endoscopy 2007; 39: 1037-1040

[20] Wei W, Ge ZZ, Lu H et al. Purgative bowel cleansing combined with simethicone improves capsule endoscopy imaging. Am J Gastroenterol 2008; 103: 77-82

[21] Wi JH, Moon JS, Choi MG et al. Bowel preparation for capsule endoscopy: a prospective randomized multicenter study. Gut Liver 2009; 3: $180-185$

[22] Pons Beltran V, Gonzalez Suarez B, Gonzalez Asanza C et al. Evaluation of different bowel preparations for small bowel capsule endoscopy: a prospective, randomized, controlled study. Dig Dis Sci 2011; 56: $2900-2905$

[23] Lapalus MG, Ben Soussan E, Saurin JC et al. Capsule endoscopy and bowel preparation with oral sodium phosphate: a prospective randomized controlled trial. Gastrointest Endosc 2008; 67: 1091-1096

[24] Park SC, Keum B, Seo YS et al. Effect of bowel preparation with polyethylene glycol on quality of capsule endoscopy. Dig Dis Sci 2011; 56 : $1769-1775$

[25] Oliva S, Cucchiara S, Spada C et al. Small bowel cleansing for capsule endoscopy in paediatric patients: a prospective randomized singleblind study. Dig Liver Dis 2014; 46: 51 - 55

[26] Niv Y. Efficiency of bowel preparation for capsule endoscopy examination: a meta-analysis. World J Gastroenterol 2008; 14: 1313-1317

[27] Rokkas T, Papaxoinis K, Triantafyllou K et al. Does purgative preparation influence the diagnostic yield of small bowel video capsule endoscopy?: A meta-analysis Am J Gastroenterol 2009; 104: 219227

[28] Kotwal VS, Attar BM, Gupta S et al. Should bowel preparation, antifoaming agents, or prokinetics be used before video capsule endoscopy? A systematic review and meta-analysis Eur J Gastroenterol Hepatol 2014; 26: $137-145$

[29] Wu S, Gao YJ, Ge ZZ. Optimal use of polyethylene glycol for preparation of small bowel video capsule endoscopy: a network meta-analysis. Curr Med Res Opin 2017; 33: 1149-1154 
[30] Koulaouzidis A, Giannakou A, Yung DE et al. Do prokinetics influence the completion rate in small bowel capsule endoscopy? A systematic review and meta-analysis Curr Med Res Opin 2013; 29: 1171 - 1185

[31] Nouda S, Morita E, Murano M et al. Usefulness of polyethylene glycol solution with imethylpolysiloxanes for bowel preparation before capsule endoscopy. J Gastroenterol Hepatol 2010; 25: 70-74

[32] Fang YH, Chen CX, Zhang BL. Effect of small bowel preparation with simethicone on capsule endoscopy. J Zhejiang Univ Sci B 2009; 10: $46-51$

[33] Albert ], Gobel CM, Lesske J et al. Simethicone for small bowel preparation for capsule endoscopy: a systematic, single-blinded, controlled study. Gastrointest Endosc 2004; 59: 487-491

[34] Wu L, Cao Y, Liao C et al. Systematic review and meta-analysis of randomized controlled trials of simethicone for gastrointestinal endoscopic visibility. Scand J Gastroenterol 2011; 46: $227-235$

[35] Yazici C, Losurdo J, Brown MD et al. In-patient capsule endoscopy leads to frequent incomplete small bowel examinations. World J Gastroenterol 2012; 18: 5051-5057

[36] Robinson CA, Jackson C, Condon D et al. Impact of in-patient status and gender on small bowel capsule endoscopy findings. Gastrointest Endosc 2011; 74: 1061-1066

[37] Shibuya T, Mori H, Takeda T et al. The relationship between physical activity level and completion rate of small bowel examination in patients undergoing capsule endoscopy. Intern Med 2012; 51: 997 1001

[38] Hosono K, Endo H, Sakai E et al. Optimal approach for small bowel capsule endoscopy using polyethylene glycol and metoclopramide with the assistance of a real-time viewer. Digestion 2011; 84: 119125

[39] Shiotani A, Honda K, Kawakami M et al. Use of an external real-time image viewer coupled with prespecified actions enhanced the complete examinations for capsule endoscopy. J Gastroenterol Hepatol 2011; 26: $1270-1274$

[40] Ogata H, Kumai K, Imaeda $\mathrm{H}$ et al. Clinical impact of a newly developed capsule endoscope: usefulness of a real-time image viewer for gastric transit abnormality. J Gastroenterol 2008; 43: 186-192

[41] Bandorski D, Kurniawan N, Baltes P et al. Contraindications for video capsule endoscopy. World J Gastroenterol 2016; 22: 9898 - 9908

[42] Bandorski D, Höltgen R, Stunder D et al. Capsule endoscopy in patients with cardiac pacemakers, implantable cardioverter defibrillators and left heart assist devices. Ann Gastroenterol 2014; 27: 3-8

[43] Bandorski D, Irnich W, Bück M et al. Capsule endoscopy and cardiac pacemakers: investigation for possible interference. Endoscopy 2008; 40: $36-39$

[44] Bandorski D, Irnich W, Brück M et al. Do endoscopy capsules interfere with implantable cardioverter-defibrillators? Endoscopy 2009; 41: $457-461$

[45] Dubner S, Dubner $\mathrm{Y}$, Rubio $\mathrm{H}$ et al. Electromagnetic interference from wireless video-capsule endoscopy on implantable cardioverter-defibrillators. Pacing Clin Electrophysiol 2007; 30: 472 - 475

[46] Bandorski D, Jakobs R, Bruck M et al. Capsule endoscopy in patients with cardiac pacemakers and implantable cardioverter defibrillators: (re)evaluation of the current state in Germany, Austria, and Switzerland 2010. Gastroenterol Res Pract 2012; 2012: 717408

[47] Payeras G, Piqueras J, Moreno VJ et al. Effects of capsule endoscopy on cardiac pacemakers. Endoscopy 2005; 37: 1181-1185

[48] Bandorski D, Diehl KL, Jaspersen D. Capsule endoscopy in patients with cardiac pacemakers: current situation in Germany. Z Gastroenterol 2005; 43: 715-718

[49] Bandorski D, Lotterer E, Hartmann D et al. Capsule endoscopy in patients with cardiac pacemakers and implantable cardioverter-defibrillators - a retrospective multicenter investigation. J Gastrointestin Liver Dis 2011; 20: 33-37
[50] Dirks MH, Costea F, Seidman EG. Successful videocapsule endoscopy in patients with an abdominal cardiac pacemaker. Endoscopy 2008; 40: $73-75$

[51] Dubner S, Dubner Y, Gallino S et al. Electromagnetic interference with implantable cardiac pacemakers by video capsule. Gastrointest Endosc 2005; 61: $250-254$

[52] Guyomar Y, Vandeville L, Heuls S et al. Interference between pacemaker and video capsule endoscopy. Pacing Clin Electrophysiol 2004; 27: $1329-1330$

[53] Harris LA, Hansel SL, Rajan E et al. Capsule endoscopy in patients with implantable electromedical devices is safe. Gastroenterol Res Pract 2013; 2013: 959234

[54] Stanich PP, Kleinman B, Betkerur K et al. Video capsule endoscopy is successful and effective in outpatients with implantable cardiac devices. Dig Endosc 2014; 26: $726-730$

[55] Leighton JA, Srivathsan K, Carey EJ et al. Safety of wireless capsule endoscopy in patients with implantable cardiac defibrillators. Am J Gastroenterol 2005; 100: 1728-1731

[56] Moneghini D, Lipari A, Missale G et al. Lack of interference between small bowel capsule endoscopy and implantable cardiac defibrillators: an 'in vivo' electrophysiological study. United European Gastroenterol J 2016; 4: $216-220$

[57] Pelargonio G, Dello Russo A, Pace M et al. Use of video capsule endoscopy in a patient with an implantable cardiac defibrillator. Europace 2006; 8: 1062 - 1063

[58] Cuschieri JR, Osman MN, Wong RC et al. Small bowel capsule endoscopy in patients with cardiac pacemakers and implantable cardioverter defibrillators: Outcome analysis using telemetry review. World ] Gastrointest Endosc 2012; 4: 87-93

[59] Leighton JA, Sharma VK, Srivathsan K et al. Safety of capsule endoscopy in patients with pacemakers. Gastrointest Endosc 2004; 59: $567-569$

[60] Zikos TA, Pan J, Limketkai B et al. Efficacy of video capsule endoscopy in the management of suspected small bowel bleeding in patients with continuous flow left ventricular assist devices. Gastroenterology Res 2017; 10: $280-287$

[61] Amornsawadwattana S, Nassif M, Raymer D et al. Video capsule endoscopy in left ventricular assist device recipients with obscure gastrointestinal bleeding. World ] Gastroenterol 2016; 22: 45594566

[62] Elmunzer B], Padhya KT, Lewis ]J et al. Endoscopic findings and clinical outcomes in ventricular assist device recipients with gastrointestinal bleeding. Dig Dis Sci 2011; 56: 3241 - 3246

[63] Meyer MM, Young SD, Sun B et al. Endoscopic evaluation and management of gastrointestinal bleeding in patients with ventricular assist devices. Gastroenterol Res Pract 2012; 2012: 630483

[64] Hanson BJ, Koene RJ, Roy SS et al. Safety and outcomes of capsule endoscopy in patients with left ventricular assist device: a singlecenter retrospective case series. J Cardiovasc Transl Res 2016; 9: $402-404$

[65] Truss WD, Weber F, Pamboukian SV et al. Early implementation of video capsule enteroscopy in patients with left ventricular assist devices and obscure gastrointestinal bleeding. ASAIO J 2016; 62: 40-45

[66] Chung JW, Hwang HJ, Chung MJ et al. Safety of capsule endoscopy using human body communication in patients with cardiac devices. Dig Dis Sci 2012; 57: 1719- 1723

[67] Pitocco D, Rizzi A, Tortora A et al. Possible radio interference between video capsule endoscopy and second-generation omnipod patch pump. Diabetes Technol Ther 2016; 18: 444-445

[68] Hogan RB, Ahmad N, Hogan RB et al. Video capsule endoscopy detection of jejunal carcinoid in life-threatening hemorrhage, first trimester pregnancy. Gastrointest Endosc 2007; 66: 205-207 
[69] Wax JR, Pinette MG, Cartin A et al. Cavernous transformation of the portal vein complicating pregnancy. Obstet Gynecol 2006; 108: 782 784

[70] Cave D, Legnani P, de Franchis R et al. ICCE consensus for capsule retention. Endoscopy 2005; 37: 1065- 1067

[71] Sachdev MS, Leighton JA, Fleischer DE et al. A prospective study of the utility of abdominal radiographs after capsule endoscopy for the diagnosis of capsule retention. Gastrointest Endosc 2007; 66: 894 - 900

[72] Dokoutsidou H, Karagiannis S, Giannakoulopoulou E et al. A study comparing an endoscopy nurse and an endoscopy physician in capsule endoscopy interpretation. Eur J Gastroenterol Hepatol 2011; 23: $166-170$

[73] Niv Y, Niv G. Capsule endoscopy examination - preliminary review by a nurse. Dig Dis Sci 2005; 50: 2121 - 2124

[74] Bossa F, Cocomazzi G, Valvano MR et al. Detection of abnormal lesions recorded by capsule endoscopy. A prospective study comparing endoscopist's and nurse's accuracy. Dig Liver Dis 2006; 38: 599-602

[75] Levinthal GN, Burke CA, Santisi JM. The accuracy of an endoscopy nurse in interpreting capsule endoscopy. Am J Gastroenterol 2003; 98: $2669-2671$

[76] Sidhu R, Sanders DS, Kapur K et al. Capsule endoscopy: is there a role for nurses as physician extenders? Gastroenterol Nurs 2007; 30: 45 48

[77] Kyriakos N, Karagiannis S, Galanis P et al. Evaluation of four time-saving methods of reading capsule endoscopy videos. Eur J Gastroenterol Hepatol 2012; 24: $1276-1280$

[78] Hosoe N, Rey JF, Imaeda H et al. Evaluations of capsule endoscopy software in reducing the reading time and the rate of false negatives by inexperienced endoscopists. Clin Res Hepatol Gastroenterol 2012; 36: $66-71$

[79] Günther U, Daum S, Zeitz M et al. Capsule endoscopy: comparison of two different reading modes. Int J Colorectal Dis 2012; 27: 521 - 525

[80] Nakamura M, Murino A, O'Rourke A et al. A critical analysis of the effect of view mode and frame rate on reading time and lesion detection during capsule endoscopy. Dig Dis Sci 2015; 60: 1743-1747

[81] Zheng Y, Hawkins L, Wolff J et al. Detection of lesions during capsule endoscopy: physician performance is disappointing. Am J Gastroenterol 2012; 107: $554-560$

[82] Zagorowicz ES, Pietrzak AM, Wronska E et al. Small bowel tumors detected and missed during capsule endoscopy: single center experience. World J Gastroenterol 2013; 19: $9043-9048$

[83] Lewis BS, Eisen GM, Friedman S. A pooled analysis to evaluate results of capsule endoscopy trials. Endoscopy 2005; 37: 960 - 965

[84] Honda W, Ohmiya N, Hirooka Y et al. Enteroscopic and radiologic diagnoses, treatment, and prognoses of small bowel tumors. Gastrointest Endosc 2012; 76: 344 - 354

[85] Worsoe J, Fynne L, Gregersen T et al. Gastric transit and small intestinal transit time and motility assessed by a magnet tracking system. BMC Gastroenterol 2011; 11: 145

[86] Koulaouzidis A, Plevris JN. Detection of the ampulla of Vater in small bowel capsule endoscopy: experience with two different systems. J Dig Dis 2012; 13: 621 - 627

[87] Selby WS, Prakoso E. The inability to visualize the ampulla of Vater is an inherent limitation of capsule endoscopy. Eur J Gastroenterol Hepatol 2011; 23: $101-103$

[88] Clarke JO, Giday SA, Magno P et al. How good is capsule endoscopy for detection of periampullary lesions? Results of a tertiary-referral center Gastrointest Endosc 2008; 68: 267-272

[89] Saurin JC, Lapalus MG, Cholet F et al. Can we shorten the small bowel capsule reading time with the "Quick-view" image detection system? Dig Liver Dis 2012; 44: 477-481
[90] Westerhof J, Koornstra J], Weersma RK. Can we reduce capsule endoscopy reading times? Gastrointest Endosc 2009; 69: 497-502

[91] Spada C, Hassan C, Costamagna G. Virtual chromoendoscopy: will it play a role in capsule endoscopy? Dig Liver Dis 2011; 43: 927-928

[92] Osawa H, Yamamoto H. Present and future status of flexible spectral imaging color enhancement and blue laser imaging technology. Dig Endosc 2014; 26: $105-115$

[93] Ryu CB, Song J, Lee MS et al. Does capsule endoscopy with Alice improves visibility of small bowel lesions? Gastrointest Endosc 2013; 77 : AB466

[94] Imagawa H, Oka S, Tanaka S et al. Improved visibility of lesions of the small intestine via capsule endoscopy with computed virtual chromoendoscopy. Gastrointest Endosc 2011; 73: 299-306

[95] Dias de Castro F, Magalhães ], Boal Carvalho P et al. Improving diagnostic yield in obscure gastrointestinal bleeding - how virtual chromoendoscopy may be the answer. Eur J Gastroenterol Hepatol 2015; 27: $735-740$

[96] Duque G, Almeida N, Figueiredo P et al. Virtual chromoendoscopy can be a useful software tool in capsule endoscopy. Rev Esp Enferm Dig 2012; 104: $231-236$

[97] Koulaouzidis A, Smirnidis A, Douglas S et al. QuickView in small bowe capsule endoscopy is useful in certain clinical settings, but QuickView with Blue Mode is of no additional benefit. Eur J Gastroenterol Hepatol 2012; 24: 1099 - 1104

[98] Nogales Rincon O, Merino Rodríguez B, González Asanza C et al. Utility of capsule endoscopy with flexible spectral imaging color enhancement in the diagnosis of small bowel lesions. Gastroenterol Hepatol 2013; 36: 63-68

[99] Sato Y, Sagawa T, Hirakawa M et al. Clinical utility of capsule endoscopy with flexible spectral imaging color enhancement for diagnosis of small bowel lesions. Endosc Int Open 2014; 2: 80 - 87

[100] Cotter J, Magalhaes J, de Castro FD et al. Virtual chromoendoscopy in small bowel capsule endoscopy: new light or a cast of shadow? World J Gastrointest Endosc 2014; 6: 359-365

[101] Rimbas M, Negreanu L, Ciobanu L et al. Is virtual chromoendoscopy useful in the evaluation of subtle ulcerative small bowel lesions detected by video capsule endoscopy? Endosc Int Open 2015; 3: 615 620

[102] Gupta T, Ibrahim M, Deviere J et al. Evaluation of Fujinon intelligent chromo endoscopy-assisted capsule endoscopy in patients with obscure gastroenterology bleeding. World J Gastroenterol 2011; 17: $4590-4595$

[103] Matsumura T, Arai M, Sato T et al. Efficacy of computed image modification of capsule endoscopy in patients with obscure gastrointestinal bleeding. World J Gastrointest Endosc 2012; 4: 421-428

[104] Koulaouzidis A, Douglas S, Plevris JN. Blue mode does not offer any benefit over white light when calculating Lewis score in small bowel capsule endoscopy. World J Gastrointest Endosc 2012; 4: 33-37

[105] Kobayashi Y, Watabe H, Yamada A et al. Efficacy of flexible spectral imaging color enhancement on the detection of small intestinal diseases by capsule endoscopy. J Dig Dis 2012; 13: 614-620

[106] Maeda M, Hiraishi H. Efficacy of video capsule endoscopy with flexible spectral imaging color enhancement at setting 3 for differential diagnosis of red spots in the small bowel. Dig Endosc 2014; 26: $228-231$

[107] Konishi M, Shibuya T, Mori H et al. Usefulness of flexible spectral imaging color enhancement for the detection and diagnosis of small intestinal lesions found by capsule endoscopy. Scand J Gastroenterol 2014; 49: $501-505$

[108] Boal Carvalho P, Magalhães ], Dias de Castro F et al. Virtual chromoendoscopy improves the diagnostic yield of small bowel capsule endoscopy in obscure gastrointestinal bleeding. Dig Liver Dis 2016; 48: $172-175$ 
[109] Abdelaal UM, Morita E, Nouda S et al. Blue mode imaging may improve the detection and visualization of small bowel lesions: A capsule endoscopy study. Saudi J Gastroenterol 2015; 21: 418-422

[110] Yung DE, Boal Carvalho P, Giannakou A et al. Clinical validity of flexible spectral imaging color enhancement (FICE) in small bowel capsule endoscopy: a systematic review and meta-analysis. Endoscopy 2017; 49: $258-269$

[111] Krystallis C, Koulaouzidis A, Douglas S et al. Chromoendoscopy in small bowel capsule endoscopy: Blue mode or Fuji Intelligent Colour Enhancement? Dig Liver Dis 2011; 43: 953 - 957

[112] Sakai E, Endo H, Kato $S$ et al. Capsule endoscopy with flexible spectral imaging color enhancement reduces the bile pigment effect and improves the detectability of small bowel lesions. BMC Gastroenterol 2012; 12: 83

[113] Ponte A, Pinho R, Rodrigues A et al. Review of small bowel cleansing scales in capsule endoscopy: a panoply of choices. World J Gastrointest Endosc 2016; 16: 600-609

[114] Gralnek IM, de Franchis R, Seidman E et al. Development of a capsule endoscopy scoring index for small bowel mucosal inflammatory change. Aliment Pharmacol Ther 2008; 27: 146-154

[115] Niv Y, Ilani S, Levi Z et al. Validation of the Capsule Endoscopy Crohn's Disease Activity Index (CECDAI or Niv score): a multicenter prospective study. Endoscopy 2012; 44: 21-26

[116] Girelli CM, Porta P, Colombo E et al. Development of a novel index to discriminate bulge from mass on small bowel capsule endoscopy. Gastrointest Endosc 2011; 74: 1067-1074

[117] Shyung LR, Lin SC, Shih SC et al. Proposed scoring system to determine small bowel mass lesions using capsule endoscopy. J Formos Med Assoc 2009; 108: 533 - 538

[118] Saurin JC, Pioche M. Why should we systematically specify the clinical relevance of images observed at capsule endoscopy? Endosc Int Open 2014; 2: 88-89

[119] Li X, Chen H, Dai J et al. Predictive role of capsule endoscopy on the insertion route of double-balloon enteroscopy. Endoscopy 2009; 41: $762-766$

[120] Delvaux M, Fassler I, Gay G. Clinical usefulness of the endoscopic video capsule as the initial intestinal investigation in patients with obscure digestive bleeding: validation of a diagnostic strategy based on the patient outcome after 12 months. Endoscopy 2004; 36: $1067-1073$

[121] Rezapour M, Amadi C, Gerson L. Retention associated with video capsule endoscopy: systematic review and meta-analysis. Gastrointest Endosc 2017; 85: 1157 -1168.e2

[122] Liao Z, Gao R, Xu C et al. Indications and detection, completion and retention rates of small bowel capsule endoscopy: a systematic review. Gastrointest Endosc 2010; 71: 280 - 286

[123] Fernandez-Urien I, Carretero C, González B et al. Incidence, clinical outcomes, and therapeutic approaches of capsule endoscopy-related adverse events in a large study population. Rev Esp Enferm Dig 2015; 107: 745-752

[124] Um S, Poblete H, Zavotsky J. Small bowel perforation caused by an impacted endocapsule. Endoscopy 2008; 40: 122-123

[125] Skovsen AP, Burchart J, Burgdorf SK. Capsule endoscopy: a cause of late small bowel obstruction and perforation. Case Rep Surg 2013; 2013: 458108

[126] Royall NA, Fiscina CD. Report of video-capsule endoscopy disruption producing episodic small bowel obstruction after prolonged retention. Int J Surg Case Rep 2014; 5: 1001 - 1004

[127] Cheifetz AS, Lewis BS. Capsule endoscopy retention: is it a complication? J Clin Gastroenterol 2006; 40: 688-691

[128] Cheon JH, Kim YS, Lee IS et al. Can we predict spontaneous capsule passage after retention? A nationwide study to evaluate the inci- dence and clinical outcomes of capsule retention Endoscopy 2007; 39: $1046-1052$

[129] Vanfleteren L, van der Schaar P, Goedhard J. Ileus related to wireless capsule retention in suspected Crohn's disease: emergency surgery obviated by early pharmacological treatment. Endoscopy 2009; 41: $134-135$

[130] Li F, Gurudu SR, De Petris G et al. Retention of the capsule endoscope: a single-center experience of 1000 capsule endoscopy procedures. Gastrointest Endosc 2008; 68: 174-180

[131] Rondonotti E, Herrerias JM, Pennazio M et al. Complications, limitations and failures of capsule endoscopy: a review of 733 cases. Gastrointest Endosc 2005; 62: 712 - 716

[132] Hoog CM, Bark LA, Arkani J et al. Capsule retentions and incomplete capsule endoscopy examinations: an analysis of 2300 examinations. Gastroenterol Res Pract 2012; 2012: 518718

[133] Sears DM, Avots-Avontins A, Culp K et al. Frequency and clinical outcome of capsule retention during capsule endoscopy for $\mathrm{Gl}$ bleeding of obscure origin. Gastrointest Endosc 2004; 60: 822-827

[134] Harrington C, Rodgers C. The longest duration of retention of a video capsule. BMJ Case Rep 2014: doi:10.1136/bcr-2013-203241

[135] Van Weyenberg SJ, Van Turenhout ST, Bouma G et al. Double-balloon endoscopy as the primary method for small bowel video capsule endoscope retrieval. Gastrointest Endosc 2010; 71: 535- 541

[136] Makipour K, Modiri AN, Ehrlich A et al. Double balloon enteroscopy: effective and minimally invasive method for removal of retained video capsules. Dig Endosc 2014; 26: 646-649

[137] Mitsui K, Fujimori S, Tanaka S et al. Retrieval of retained capsule endoscopy at small bowel stricture by double-balloon endoscopy significantly decreases surgical treatment. | Clin Gastroenterol 2016; 50: 141 - 146

[138] Koulaouzidis A, Rondonotti E, Karargyris A. Small bowel capsule endoscopy: a ten-point contemporary review. World J Gastroenterol 2013; 19: $3726-3746$

[139] Despott E], O'Rourke A, Anikin V et al. Tracheal aspiration of capsule endoscopes: detection, management, and susceptibility. Dig Dis Sci 2012; 57: $1973-1974$

[140] Yung DE, Plevris JN, Koulaouzidis A. Short article: Aspiration of capsule endoscopes: a comprehensive review of the existing literature. Eur J Gastroenterol Hepatol 2017; 29: 428-434

[141] Holden JP, Dureja P, Pfau PR et al. Endoscopic placement of the small bowel video capsule by using a capsule endoscope delivery device. Gastrointest Endosc 2007; 65: 842-847

[142] Almeida N, Figueiredo P, Lopes S et al. Capsule endoscopy assisted by traditional upper endoscopy. Rev Esp Enferm Dig 2008; 100: $758-763$

[143] Carey EJ, Heigh RI, Fleischer DE. Endoscopic capsule endoscope delivery for patients with dysphagia, anatomical abnormalities, or gastroparesis. Gastrointest Endosc 2004; 59: 423 - 426

[144] Rondonotti E, Soncini M, Girelli C et al. Small bowel capsule endoscopy in clinical practice: a multicentre 7-years survey. Eur ] Gastroenterol 2010; 22: $1380-1386$

[145] Postgate AJ, Burling D, Gupta A et al. Safety, reliability and limitations of the given patency capsule in patients at risk of capsule retention: a 3-year technical review. Dig Dis Sci 2008; 53: 2732-2738

[146] Al-Bawardy B, Locke G, Huprich JE et al. Retained capsule endoscopy in a large tertiary care academic practice and radiologic predictors of retention. Inflamm Bowel Dis 2015; 21: 2158 -2164

[147] Signorelli C, Rondonotti E, Villa F et al. Use of the Given Patency System for the screening of patients at high risk for capsule retention. Dig Liver Dis 2006; 38: $326-330$

[148] Du J, Pan D, Ma P et al. The clinical characteristic and risk of capsule incomplete and retention in Crohn's disease. Int J Clin Exp Med 2015; 5: $13482-90$ 
[149] Spada C, Spera G, Riccioni M et al. A novel diagnostic tool for detecting functional patency of the small bowel: the Given patency capsule. Endoscopy 2005; 37: 793-800

[150] Zhang W, Han ZL, Cheng Y et al. Value of the patency capsule in preevaluation for capsule endoscopy in cases of intestinal obstruction. J Dig Dis 2014; 15: $345-351$

[151] Yadav A, Heigh RI, Hara AK et al. Performance of the patency capsule compared with nonenteroclysis radiologic examinations in patients with known or suspected intestinal strictures. Gastrointest Endosc 2011; 74: 834-839

[152] Rondonotti E, Soncini M, Girelli CM et al. Short article: Negative small bowel cross-sectional imaging does not exclude capsule retention in high-risk patients. Eur J Gastroenterol Hepatol 2016; 28: $871-875$

[153] Kopylov U, Nemeth A, Cebrian A et al. Symptomatic retention of the patency capsule: a multicenter real life case series. Endosc Int Open 2016; 4: $964-969$

[154] Chokshi RV, Hovis CE, Hollander T et al. Prevalence of missed adenomas in patients with inadequate bowel preparation on screening colonoscopy. Gastrointest Endosc 2012; 75: 1197-1203

[155] Phillips SF. Functions of the large bowel: an overview. Scand J Gastroenterol Suppl 1984; 93: 1-12

[156] Spiller RC. Intestinal absorptive function. Gut 1994; 35: S5 - S9

[157] Volk N, Lacy B. Anatomy and physiology of the small bowel. Gastrointest Endosc Clin N Am 2017; 27: 1 - 13

[158] Lin MC, Chen PJ, Shih YL et al. Outcome and safety of anterograde and retrograde single-balloon enteroscopy: clinical experience at a tertiary medical center in Taiwan. PLoS One 2016; 11: e0161188

[159] Lenz P, Roggel M, Domagk D. Double- vs. single-balloon enteroscopy: single center experience with emphasis on procedural performance. Int J Colorectal Dis 2013; 28: 1239-1246

[160] May A, Nachbar L, Ell C. Double-balloon enteroscopy (push-and-pull enteroscopy) of the small bowel: feasibility and diagnostic and therapeutic yield in patients with suspected small bowel disease. Gastrointest Endosc 2005; 62: 62-70

[161] Yamamoto H, Kita H, Sunada K et al. Clinical outcomes of doubleballoon endoscopy for the diagnosis and treatment of small-intestinal diseases. Clin Gastroenterol Hepatol 2004; 2: 1010-1016

[162] Hassan C, Bretthauer M, Kaminski MF et al. Bowel preparation for colonoscopy: European Society of Gastrointestinal Endoscopy (ESGE) guideline. Endoscopy 2013; 45: 142 - 150

[163] Johnson DA, Barkun AN, Cohen LB et al. Optimizing adequacy of bowel cleansing for colonoscopy: recommendations from the US multi-society task force on colorectal cancer. Gastroenterology 2014; 147: 903 - 924

[164] Aniwan S, Viriyautsahakul V, Angsuwatcharakon P et al. Comparison of urgent video capsule endoscopy and urgent double-balloon endoscopy in massive obscure gastrointestinal bleeding. Hepatogastroenterology 2014; 61: 1990-1994

[165] Monkemuller K, Neumann $\mathrm{H}$, Meyer $\mathrm{F}$ et al. A retrospective analysis of emergency double-balloon enteroscopy for small-bowel bleeding. Endoscopy 2009; 41: $715-717$

[166] Mensink PB, Haringsma J, Kucharzik T et al. Complications of double balloon enteroscopy: A multicenter survey. Endoscopy 2007; 39: $613-615$

[167] Gerson LB, Tokar J, Chiorean M et al. Complications associated with double balloon enteroscopy at nine US centers. Clin. Gastroenterol Hepatol 2009; 7: $1177-1182$

[168] Möschler O, May A, Muller MK et al. Complications in and performance of double-balloon enteroscopy (DBE): Results from a large prospective DBE database in Germany. Endoscopy 2011; 43: 484 489

[169] Despott EJ, Murino A, Hughes S et al. Second report of the UK multicentre DBE registry: furthering the international DBE experience. Gastrointest Endosc 2011; 73: AB394

[170] Rondonotti E, Sunada K, Yano T et al. Double-balloon endoscopy in clinical practice: where are we now? Dig Endosc 2012; 24: 209 - 219

[171] Moeschler O, Mueller MK. Deep enteroscopy - indications, diagnostic yield and complications. World J Gastroenterol 2015; 21: 1385 1393

[172] Cotton PB, Eisen GM, Aabakken L et al. A lexicon for endoscopic adverse events: report of an ASGE workshop. Gastrointest Endosc 2010; 71: $446-454$

[173] Hirai F, Beppu T, Sou S et al. Endoscopic balloon dilatation using double-balloon endoscopy is a useful and safe treatment for small intestinal strictures in Crohn's disease. Dig Endosc 2010; 22: 200 204

[174] Xin L, Liao Z, Jiang YP et al. Indications, detectability, positive findings, total enteroscopy and complications of diagnostic double-balIoon endoscopy: a systematic review of data over the first decade of use. Gastrointest Endosc 2011; 74: 563 - 570

[175] Möschler O, May AD, Müller MK et al. Complications in double-balIoon-enteroscopy: results of the German DBE register. DBE-Studiengruppe Deutschland. Z Gastroenterol 2008; 46: 266 - 270

[176] Teshima CW, Aktas H, Kuipers EJ et al. Hyperamylasemia and pancreatitis following spiral enteroscopy. Can J Gastroenterol 2012; 26 : $603-606$

[177] Zepeda-Gomez S, Barreto-Zuniga R et al. Risk of hyperamylasemia and acute pancreatitis after double-balloon enteroscopy: a prospective study. Endoscopy 20143: 766 - 770

[178] Tsujikawa T, Bamba S, Inatomi O et al. Factors affecting pancreatic hyperamylasemia in patients undergoing peroral single-balloon enteroscopy. Dig Endosc 2015; 27: 674-678

[179] Kopacova M, Tacheci I, Rejchrt S etal. Double balloon enteroscopy and acute pancreatitis. World J Gastroenterol 2010 2116: 2331 2340

[180] Pata C, Akyuz U, Rzin Y et al. Post-procedure elevated amylase and lipase levels after double-balloon enteroscopy: relations with the double-balloon technique. Dig Dis Sci 2010; 55: $1982-1988$

[181] Judah JR, Draganov PV, Lam Y et al. Spiral enteroscopy is safe and effective for an elderly United States population of patients with numerous comorbidities. Clin Gastroenterol Hepatol 2010; 8: 572 576

[182] Akerman PA, Cantero D. Spiral enteroscopy and push enteroscopy. Gastrointest Endosc Clin N Am 2009; 19: 357-369

[183] Chavalitdhamrong D, Adler DG, Draganov PV. Complications of enteroscopy: how to avoid them and manage them when they arise. Gastrointest Endosc Clin N Am 2015; 25: 83 - 95

[184] Khashab MA, Lennon AM, Dunbar KB et al. A comparative evaluation of single-balloon enteroscopy and spiral enteroscopy for patients with mid-gut disorders. Gastrointest Endosc 2010; 72: 766-772

[185] Davis-Yadley AH, Lipka S, Rodriguez AC et al. The safety and efficacy of single balloon enteroscopy in the elderly. Therap Adv Gastroenterol 2016; 9: $169-179$

[186] Manno M, Riccioni ME, Cannizzaro R et al. Diagnostic and therapeutic yield of single balloon enteroscopy in patients with suspected small-bowel disease: results of the Italian multicentre study. Dig Liver Dis 2013; 45: $211-215$

[187] Shinozaki S, Yamamoto H, Yano T et al. Long-term outcome of patients with obscure gastrointestinal bleeding investigated by dou- 
ble-balloon endoscopy. Clin Gastroenterol Hepatol 2010; 8: 151 158

[188] Byeon J-S, Mann NK, Jamil LH et al. Double balloon enteroscopy can be safely done in elderly patients with significant co-morbidities. J Gastroenterol Hepatol 2012; 27: 1831 - 1836

[189] Sidhu R, Sanders DS. Double-balloon enteroscopy in the elderly with obscure gastrointestinal bleeding: safety and feasibility. Eur J Gastroenterol Hepatol 2013; 25: 1230 - 1234

[190] Akarsu M, Akkaya Ozdinç S, Celtik A et al. Diagnostic and therapeutic efficacy of double-balloon endoscopy in patients with small intestinal diseases: single-center experience in 513 procedures. Turk J Gastroenterol 2014; 25: 374-380

[191] Lahat A, Nadler M, Simon C et al. Double balloon enteroscopy: a 2 year experience. Isr Med Assoc J 2009; 11: 456-459

[192] Disibeyaz S, Suna N, Kuzu UB et al. Double balloon enteroscopy: A 7year experience at a tertiary care Centre. Eur J Intern Med 2016; 33 : $108-111$

[193] Choi DH, Jeon SR, Kim JO et al. Double-balloon enteroscopy in elderly patients: is it safe and useful? Intest Res 2014; 12: $313-319$

[194] Cazzato IA, Cammarota G, Nista EC et al. Diagnostic and therapeutic impact of double-balloon enteroscopy (DBE) in a series of 100 patients with suspected small bowel diseases. Dig Liver Dis 2007; 39: $483-487$

[195] Yang DH. Questions about sedation protocols for double-balloon enteroscopy. Intest Res 2015; 13: 97 - 98

[196] Zubek L, Szabo L, Lakatos PL et al. Double balloon enteroscopy examinations in general anesthesia. World J Gastroenterol 2010; 16: $3418-3422$

[197] Sethi S, Thaker AM, Cohen J et al. Monitored anesthesia care without endotracheal intubation is safe and efficacious for single-balloon enteroscopy. Dig Dis Sci 2014; 59: 2184-2190

[198] Jensen JT, Hornslet P, Konge L et al. High efficacy with deep nurseadministered propofol sedation for advanced gastroenterologic endoscopic procedures. Endosc Int Open 2016; 4: E107-E111

[199] Kawano S, Okada H, Iwamuro M et al. An effective and safe sedation technique combining target-controlled infusion pump with propofol, intravenous pentazocine, and bispectral index monitoring for peroral double-balloon endoscopy. Digestion 2015; 91: 112 - 116

[200] Judah JR, Collins D, Gaidos JK et al. Prospective evaluation of gastroenterologist-guided, nurse-administered standard sedation for spiral deep small bowel enteroscopy. Dig Dis Sci 2010; 55: 2584 2591

[201] American Society of Anesthesiologists. ASA Physical Status Classification System. Available at: https://www.asahq.org/resources/clinical-information/asa-physical-status-classification-system Accessed March 2017

[202] Murino A, Nakamura M, Despott E] et al. Factors associated with reduced insertion depth at double balloon enteroscopy: a retrospective, multivariate analysis. Dig Liver Dis 2014; 46: 956 - 958

[203] Tanaka S, Mitsui K, Tatsuguchi A et al. Current status of double balIoon endoscopy-indications, insertion route, sedation, complications, technical matters. Gastrointest Endosc 2007; 66: S30-S33

[204] Gay G, Delvaux M, Fassler I. Outcome of capsule endoscopy in determining indication and route for push-and-pull enteroscopy. Endoscopy 2006; 38: 49 - 58

[205] Mandaliya R, Korenblit J, O’Hare B et al. Spiral enteroscopy utilizing capsule location index for achieving high diagnostic and therapeutic yield. Diagn Ther Endosc 2015: 793516

[206] Sanaka M, Navaneethan U, Kosuru B et al. Antegrade is more effective than retrograde enteroscopy for evaluation and management of suspected small bowel disease. Clin Gastroenterol Hepatol 2012: $910-916$

[207] Akyuz U, Pata C, Kalayci M et al. Route selection for double balloon enteroscopy in patients with obscure gastrointestinal bleeding: experience from a single center. Turk J Gastroenterol 2012; 23: 670 675

[208] Kaufman D, Leslie G, Marya N et al. Small intestinal angioectasia: characterization, risk factors, and rebleeding. J Clin Gastroenterol 2016; $51: 720-727$

[209] Plotkin E, Imaeda A. Small intestinal angioectasias are not randomly distributed in the small bowel and most may be reached by push enteroscopy. J Clin Gastroenterol 2016; 50: 561 - 565

[210] Bollinger E, Raines D, Saitta P. Distribution of bleeding gastrointestinal angioectasias in Western population. World J Gastroenterol 2012; 18: 6235-6239

[211] Jackson C, Strong R. Gastrointestinal angiodysplasia: diagnosis and management. Gastrointest Endosc Clin N Am 2017; 27: 51 -62

[212] Despott EJ, Fraser C. Small bowel endoscopy in inflammatory bowel disease. Best Pract Res Clin Gastroenterol 2012; 26: 279-291

[213] Pape UF, Perren A, Niederle B et al. ENETS consensus guidelines for the management of patients with neuroendocrine neoplasms from the jejuno-ileum and the appendix including goblet cell carcinomas. Neuroendocrinology 2012; 95: 135-156

[214] Messer I, May A, Manner $\mathrm{H}$ et al. Prospective, randomized, singlecenter trial comparing double-balloon enteroscopy and spiral enteroscopy in patients with suspected small bowel disorders. Gastrointest Endosc 2013; 77: 241 - 249

[215] Teshima CW, Aktas H, van Buuren HR et al. Retrograde double balloon enteroscopy: comparing performance of solely vs. combined same-day anterograde and retrograde procedure. Scand J Gastroenterol 2011; 36: $220-226$

[216] May A, Nachbar L, Schneider M et al. Push-and-pull enteroscopy using the double-balloon technique: method of assessing depth of insertion and training of the enteroscopy. Endoscopy 2005; 37: 66 70

[217] Zhong J, Ma T, Zhang C et al. A retrospective study of the application on double-balloon enteroscopy in 378 patients with suspected small-bowel diseases. Endoscopy 2007; 39: 208 - 215

[218] Lopez AO, Soria F, Perez Cuadrado E et al. Validity of insertion depth measurement in double-balloon endoscopy. Endoscopy 2012; 44 : $1045-1050$

[219] Efthymiou M, Desmond PV, Brown G et al. SINGLE-01: a randomized, controlled trial comparing the efficacy and depth of insertion of single- and double-balloon enteroscopy by using a novel method to determine insertion depth. Gastrointest Endosc 2012; 76: 972 - 980

[220] Li XB, Chen HM, Zhuang J et al. A novel modality for the estimation of the enteroscope insertion depth during double-balloon enteroscopy. Gastrointest Endosc 2010; 72: 999-1005

[221] Manno M, Barbera C, Bertani H et al. Single balloon enteroscopy: technical aspects and clinical applications. World J Gastrointest Endosc 2012; 4: 28-32

[222] Akerman P, Agrawal D, Cantero D et al. Spiral enteroscopy with the new DSB overtube: a novel technique for deep peroral small bowel intubation. Endoscopy 2008; 40: 974-978

[223] Domagk D, Mensink P, Aktas H et al. Single- vs. double-balloon enteroscopy in small bowel diagnostics: a randomized multicenter trial. Endoscopy 2011; 43: 472-476

[224] Takano N, Yamada A, Watabe H et al. Single-balloon vs. double-balloon endoscopy for achieving total enteroscopy: a randomized, controlled trial. Gastrointest Endosc 2011; 73: 734-739

[225] Wadhwa V, Sethi S, Tewani S et al. A meta-analysis on efficacy and safety: single-balloon vs. double-balloon enteroscopy. Gastroenterol Rep 2015; 3: $148-155$ 
[226] Lipka S, Rabbanifard R, Kumar A et al. Single vs. double balloon enteroscopy for small bowel diagnostics: a systematic review and meta-analysis. J Clin Gastroenterol 2015; 49: 177-184

[227] Lenz P, Domagk D. Double- vs. single-balloon vs. spiral enteroscopy. Best Pract Res Clin Gastroenterol 2012; 26: $303-313$

[228] Despott E], Murino A, Bourikas L et al. A prospective comparison of performance during back-to-back, anterograde manual spiral enteroscopy and double-balloon enteroscopy. Dig Liver Dis 2015; 47: $395-400$

[229] May A, Manner H, Aschmoneit I et al. Prospective, cross-over, singlecenter trial comparing oral double-balloon enteroscopy and oral spiral enteroscopy in patients with suspected small bowel vascular malformations. Endoscopy 2011; 43: 477-483

[230] May A, Farber M, Aschmoneit I et al. Prospective multicenter trial comparing push-and-pull enteroscopy with the single- and doubleballoon techniques in patients with small bowel disorders. Am J Gastroenterol 2010; 105: 575-581

[231] May A. Double-balloon enteroscopy. Gastrointest Endosc Clin N Am 2017; 27: $113-122$

[232] Lenz P, Domagk D. Single-balloon enteroscopy. Gastrointest Endosc Clin N Am27: 123-131

[233] Tee HP, How SH, Kaffes AJ. Learning curve for double-balloon enteroscopy: findings from an analysis of 282 procedures. World J Gastrointest Endosc 2012; 4: 368 - 372

[234] Mehdizadeh S, Ross A, Gerson L et al. What is the learning curve associated with double-balloon enteroscopy? Technical details and early experience in 6 U.S. tertiary care centers Gastrointest Endosc 2006; 64: $740-750$

[235] Manner H, May A, Pohl J et al. The impact of fluoroscopy on the outcome of oral double-balloon enteroscopy: results of a randomized trial in 156 patients. Endoscopy 2010; 42: 820-826

[236] Lo SK. Technical matters in double balloon enteroscopy. Gastrointest Endosc 2007; 66: S15-S18

[237] May A, Nachbar L, Pohl J et al. Endoscopic interventions in the small bowel using double-balloon enteroscopy: feasibility and limitations. Am J Gastroenterol 2007; 102: 527-535

[238] ASGE Technology Committee, Lo SK, Fujii-Lau LL et al. The use of carbon dioxide in gastrointestinal endoscopy. Gastrointest Endosc 2016; 83: 857-865

[239] Domagk D, Bretthauer M, Lenz P et al. Carbon dioxide insufflation improves intubation depth in double-balloon enteroscopy: a randomized, controlled, double-blind trial. Endoscopy 2007; 39: 1064 1067

[240] Hirai F, Beppu T, Nishimura T et al. Carbon dioxide insufflation compared with air insufflation in double balloon enteroscopy: a prospective, randomized, double-blind trial. Gastrointest Endosc 2011; 73: $743-749$

[241] Lenz P, Meister T, Manno M et al. CO2 insufflation during single-balloon enteroscopy: A multicenter randomized controlled trial. Endoscopy 2014; 46: 53- 58

[242] Li X, Zhao Y], Dai J et al. Carbon dioxide insufflation improves the intubation depth and total enteroscopy rate in single-balloon enteroscopy: A randomised, controlled, double-blind trial. Gut 2014; 63: $1560-1565$

[243] Nishizawa T, Suzuki H, Fujimoto A et al. Effects of carbon dioxide insufflation in balloon-assisted enteroscopy: A systematic review and meta-analysis. United European Gastroenterol ] 2016; 4: 11 -7

[244] Bretthauer M, Thiis-Evensen E, Huppertz-Hauss G et al. NORCCAP (Norwegian colorectal cancer prevention): a randomised trial to as- sess the safety and efficacy of carbon dioxide vs. air insufflation in colonoscopy. Gut 2002; 50: 604-607

[245] Saito Y, Uraoka T, Matsuda T et al. A pilot study to assess the safety and efficacy of carbon dioxide insufflation during colorectal endoscopic submucosal dissection with the patient under conscious sedation. Gastrointest Endosc 2007; 65: 537-542

[246] Sumanac K, Zealley I, Fox BM et al. Minimizing postcolonoscopy abdominal pain by using $\mathrm{CO} 2$ insufflation: a prospective, randomized, double blind, controlled trial evaluating a new commercially available CO2 delivery system. Gastrointest Endosc 2002; 56: 190-194

[247] Bretthauer M, Lynge AB, Thiis-Evensen E et al. Carbon dioxide insufflation in colonoscopy: safe and effective in sedated patients. Endoscopy 2005; 37: $706-709$

[248] Soria F, Lopez-Albors O, Morcillo E et al. Carbon dioxide insufflation safety in double-balloon enteroscopy: an experimental animal study. Dig Endosc 2013; 25: 39-46

[249] Anderson JC. Water-aided colonoscopy. Gastrointest Endosc Clin N Am 2015; 25: $211-226$

[250] Hafner S, Zolk K, Radaelli F et al. Water infusion vs. air insufflation for colonoscopy. Cochrane Database Syst Rev 2015; 26: CD009863

[251] Cadoni S, Falt P, Rondonotti E et al. Water exchange for screening colonoscopy increases adenoma detection rate: a multicenter, double-blinded, randomized controlled trial. Endoscopy 2017; 49: 456 467

[252] Liang S, Pan Y, Wang B et al. Water exchange method improves the total examination rate of single balloon enteroscopy: a prospective, randomized, controlled trial. Gastrointest Endosc 2016; 83: AB161 AB162

[253] Westwood DA, Alexakis N, Connor S]. Transparent cap-assisted colonoscopy vs. standard adult colonoscopy: a systematic review and meta-analysis. Dis Colon Rectum 2012; 55: 218-225

[254] Sanchez-Yague A, Kaltenbach T, Yamamoto $\mathrm{H}$ et al. The endoscopic cap that can (with videos). Gastrointest Endosc 2012; 76: 169-178

[255] Dufault DL, Brock AS. Cap-assisted retrograde single-balloon enteroscopy results in high terminal ileal intubation rate. Endosc Int Open 2016; 4: E202-E204

[256] Misra SP, Dwivedi M. Role of intravenously administered hyoscine butyl bromide in retrograde terminal ileoscopy: a randomized, double-blinded, placebo-controlled trial. World J Gastroenterol 2007; 13: $1820-1823$

[257] Ell C, May A, Nachbar L et al. Push-and-pull enteroscopy in the smal bowel using the double-balloon technique: results of a prospective European multicenter study. Endoscopy 2005; 37: 613-616

[258] Heine GD, Hadithi M, Groenen M] et al. Double-balloon enteroscopy: indications, diagnostic yield, and complications in a series of 275 patients with suspected small-bowel disease. Endoscopy 2006; 38: $42-48$

[259] Sun B, Rajan E, Cheng S et al. Diagnostic yield and therapeutic impact of double-balloon enteroscopy in a large cohort of patients with obscure gastrointestinal bleeding. Am J Gastroenterol 2006; 101: $2011-2015$

[260] Ramchandani M, Reddy DN, Gupta R et al. Diagnostic yield and therapeutic impact of single-balloon enteroscopy: series of 106 cases. J Gastroenterol Hepatol 2009; 24: 1631-1638

[261] Aktas H, de Ridder L, Haringsma J et al. Complications of single-balloon enteroscopy: a prospective evaluation of 166 procedures. Endoscopy 2010; 42: 365-368

[262] Frantz D], Dellon ES, Grimm I et al. Single-balloon enteroscopy: results from an initial experience at a U.S. tertiary-care center. Gastrointest Endosc 2010; 72: $422-426$

[263] Upchurch BR, Sanaka MR, Lopez AR et al. The clinical utility of singleballoon enteroscopy: a single-center experience of 172 procedures. Gastrointest Endosc 2010; 71: $1218-1223$ 
[264] Morgan D, Upchurch BR, Draganov PV et al. Spiral enteroscopy: prospective multicenter U.S. trial in patients with small bowel disorders. Gastrointest Endosc 2010; 72: 992 - 998

[265] Hartmann D, Schmidt H, Bolz G et al. A prospective two-center study comparing wireless capsule endoscopy with intraoperative enteroscopy in patients with obscure Gl bleeding. Gastrointest Endosc 2005; 61: 826-832

[266] Despott EJ, Gupta A, Burling D et al. Effective dilation of small bowel strictures by double-balloon enteroscopy in patients with symptomatic Crohn's disease (with video). Gastrointest Endosc 2009; 70: $1030-1036$

[267] Despott E], Gabe S, Tripoli E et al. Enteral access by double-balloon enteroscopy: an alternative method of direct percutaneous endoscopic jejunostomy placement. Dig Dis Sci 2011; 56: 494-498

[268] Gómez V, Petersen BT. Endoscopic retrograde cholangiopancreatography in surgically altered anatomy. Gastrointest Endosc Clin N Am 2015; 25: 631-656

[269] Ishii K, Itoi T, Tonozuka R. Balloon enteroscopy-assisted ERCP in patients with Roux-en-Y gastrectomy and intact papillae (with videos). Gastrointest Endosc 2016; 83: 377-386

[270] May A. How to approach the small bowel with flexible enteroscopy. Gastroenterol Clin North Am 2010; 39: 797-806

[271] Finkelstone L, Wolf E, Stein MW. Etiology of small bowel thickening on computed tomography. Can J Gastroenterol 2012; 26: 897-901

[272] Fraser C, Despott EJ. Peutz-Jeghers syndrome. In: Keuchel M, Hagenmüller F, Hisao T, eds. Video capsule endoscopy: a reference guide and atlas. Dordrecht: Springer Science and Business Media; 2014

[273] Despott E], Fraser C. Capsule endoscopy in polyposis syndromes. In: Zhao-Shen L, Zhuan L, McAlindon M , eds. Handbook of capsule endoscopy. Dordrecht: Springer Science and Business Media; 2014

[274] Pohl J, May A, Nachbar L et al. Diagnostic and therapeutic yield of push-and-pull enteroscopy for symptomatic small bowel Crohn's disease strictures. Eur J Gastroenterol Hepatol 2007; 19: 529-534

[275] Sunada K, Yamamoto H, Yano T et al. Advances in the diagnosis and treatment of small bowel lesions with Crohn's disease using doubleballoon endoscopy. Therap Adv Gastroenterol 2009; 2: 357-366

[276] Thienpont C, D'Hoore A, Vermeire $S$ et al. Long-term outcome of endoscopic dilatation in patients with Crohn's disease is not affected by disease activity or medical therapy. Gut 2010; 59: 320-324
[277] Beaulieu D, Barkun AN, Dubé C et al. Endoscopy reporting standards. Can J Gastroenterol 2013; 27: 286-292

[278] Rizk MK, Sawhney MS, Cohen J et al. Quality indicators common to all Gl endoscopic procedures. Gastrointest Endosc 2015; 81: 3-16

[279] Bretthauer M, Aabakken L, Dekker E et al. Requirements and standards facilitating quality improvement for reporting systems in gastrointestinal endoscopy: European Society of Gastrointestinal Endoscopy (ESGE) Position Statement. Endoscopy 2016; 48: 291 294

[280] Veitch AM, Vanbiervliet G, Gershlick AH et al. Endoscopy in patients on antiplatelet or anticoagulant therapy, including direct oral anticoagulants: British Society of Gastroenterology (BSG) and European Society of Gastrointestinal Endoscopy (ESGE) guidelines. Endoscopy 2016; 48: 385-402

[281] Itaba S, Nakamura K, Aso A et al. Prospective, randomized, doubleblind, placebo-controlled trial of ulinastatin for prevention of hyperenzymemia after double balloon endoscopy via the antegrade approach. Dig Endosc 2013; 25: 421 - 427

[282] Groenen MJ, Moreels TG, Orlent $\mathrm{H}$ et al. Acute pancreatitis after double-balloon enteroscopy: an old pathogenetic theory revisited as a result of using a new endoscopic tool. Endoscopy 2006; 38: $82-85$

[283] Matsushita M, Shimatani M, Uchida K et al. Mechanism of acute pancreatitis after peroral double-balloon enteroscopy. Endoscopy 2007; 39: 480

[284] Latorre R, Soria F, Lopez-Albors O et al. Effect of double-balloon enteroscopy on pancreas: an experimental porcine model. World J Gastroenterol 2012; 18: 5181-5187

[285] Honda K, Itaba S, Mizutani T et al. An increase in the serum amylase level in patients after peroral double-balloon enteroscopy: an association with the development of pancreatitis. Endoscopy 2006; 38: $1040-1043$

[286] European Section and Board of Gastroenterology and Hepatology. The Blue Book. Available at: http://www.eubogh.org/blue-book/ Accessed: March 2017

[287] ASGE Training Committee 2011-2012, Rajan EA, Pais SA et al. Smallbowel endoscopy core curriculum. Gastrointest Endosc 2013; 77: $1-6$

[288] Sidhu R, Sanders DS, Morris AJ et al. Guidelines on small bowel enteroscopy and capsule endoscopy in adults. Gut 2008; 57: 125 136 